\title{
Regime Político e Sistema de Inteligência no Brasil: Legitimidade e Efetividade como Desafios Institucionais*
}

\author{
Marco Cepik
}

\section{INTRODUÇÃO}

$\mathrm{N}$ este texto, discuto as mudanças ocorridas na área de inteligência no âmbito do governo brasileiro entre 1999 e 2004. Tal discussão tem dois objetivos principais: $1^{\circ}$ ) debater a relação entre desempenho agregado dos regimes políticos democráticos (capacidade estatal e legitimidade) e as instituições da área de segurança. Dado o foco do trabalho em um tipo específico de instituição governamental (serviços de inteligência), importa saber o quanto as variações observadas em um país qualquer - na forma como as atividades de inteligência são legalmente definidas e no modo de organizar tais atividades - são congruentes com a natureza do regime político vigente. Por outro lado, como os diferentes níveis de efetividade e legitimidade das atividades de inteligência afetam o desempenho do regime políti-

\footnotetext{
*Uma versão resumida deste trabalho foi apresentada no seminário Intelligence and Democracy: A Work in Progress, realizado em 26-27 de agosto de 2004, no Center for Civil-Military Relations - CCMR da Naval Postgraduate School - NPS, em Monterey, California. Os demais trabalhos e a lista dos participantes do seminário podem ser obtidos em <www.ccmr.org > . Gostaria de agradecer os comentários dos participantes do seminário, especialmente seus organizadores, professores Thomas Bruneau e Kenneth Dombroski. Gostaria ainda de agradecer a decisiva colaboração de Priscila Antunes, Edisom Hott, Ariel Mendonça e Luis Carlos Guedes. Obviamente, a responsabilidade pelo texto é exclusivamente minha.
}

DADOS - Revista de Ciências Sociais, Rio de Janeiro, Vol. 48, n1, 2005, pp. 67 a 113. 
co como um todo ${ }^{1}$. ${ }^{\circ}$ ) sistematizar e atualizar as informações dispersas que existem sobre essas agências governamentais no caso do Brasil, de modo que os leitores interessados possam ter uma visão geral dos processos em curso, suas realizações e também seus limites ${ }^{2}$.

O argumento aqui desenvolvido está organizado em quatro partes. Nesta introdução são explicitadas duas premissas gerais e a hipótese que orientou a pesquisa. Em seguida, discute-se brevemente a natureza do regime político brasileiro atual e alguns indicadores de desempenho relevantes para a compreensão da atividade de inteligência. Na terceira parte são apresentadas as mudanças na conformação organizacional e legal do sistema de inteligência deste país ao longo do período 1999-2004. Finalmente, na conclusão, são resumidas as principais descobertas da pesquisa.

A primeira premissa adotada aqui supõe que a existência de serviços de inteligência institucionalizados, isto é, legítimos e efetivos, é condição necessária para um Estado democrático garantir a segurança dos cidadãos e promover o interesse público. Nesse sentido, serviços de inteligência são parte essencial, juntamente com as Forças Armadas, as polícias e a diplomacia, do aparato burocrático de qualquer Estado com pretensões mínimas de autonomia no sistema internacional. Estados com regimes políticos democráticos não são excepcionais, no sentido de que poderiam prescindir desse tipo de capacidade ou $\operatorname{poder}^{3}$ (cf. Barry, 1991).

A segunda premissa diz respeito à tensão existente entre os requisitos de segurança impostos a qualquer país em função da estrutura anárquica do sistema internacional (self-help e ganhos relativos) e os critérios mínimos da democracia enquanto regime político. Além dos problemas comuns de controle democrático que existem em outras áreas de atuação do Estado, também caracterizadas por complexidade tecnológica e organizacional, na segurança há tensões e dificuldades específicas que podem ser sintetizadas pela dupla dicotomia segurança estatal versus segurança individual e segredo governamental versus direito à informação. Obviamente, ambas as dicotomias não são características exclusivas dos países semiperiféricos e periféricos, ou que passaram por regimes autoritários de governo há menos de vinte anos, manifestando-se de maneira mais ou menos intensa também nos países mais poderosos, ricos e democráticos do mundo ${ }^{4}$. 
Considero, entretanto, que o duplo desafio da legitimidade e da efetividade dos serviços de inteligência é particularmente decisivo nas chamadas "novas democracias" como o Brasil, exatamente pela experiência do regime militar e pelos desafios recentes na área de segurança pública e inserção internacional ${ }^{5}$.

Segundo a hipótese de trabalho que orientou a pesquisa, embora o regime político brasileiro seja democrático e consolidado segundo critérios mínimos, a capacidade estatal do país ainda é relativamente baixa, o que se traduz no grau de efetividade das novas estruturas de inteligência que começaram a ser implementadas a partir de 1999. Na fase atual de desenvolvimento político do país, uma persistente vulnerabilidade em termos de capacidade estatal na área de provimento de defesa nacional e segurança pública tende a ser deletéria tanto para a estabilidade quanto para a qualidade da democracia. Nesse sentido, conquanto a legitimidade e a efetividade dos serviços de inteligência sejam dois lados da mesma moeda, no caso brasileiro os desafios atuais de institucionalização desses serviços estão mais fortemente associados à efetividade e eficiência do que à legitimidade ${ }^{6}$.

\section{A NATUREZA DO REGIME POLÍTICO E A CAPACIDADE DO ESTADO NO BRASIL}

Adoto como ponto de partida quatro condições necessárias e suficientes para caracterizar um regime político como democrático: 1) os dirigentes dos Poderes Executivo e Legislativo são selecionados com base em eleições periódicas, competitivas e consideradas limpas pelos participantes e observadores externos aceitos pelos candidatos; 2) os direitos políticos de votar e ser votado são extensivos a toda a população adulta; 3 ) os direitos políticos e civis básicos (expressão, organização e integridade física) de cada cidadão não são violados sem que os governantes sejam responsabilizados política e judicialmente; 4) os representantes eleitos podem governar sem a tutela de grupos de poder não eleitos, sejam eles militares, empresários, governos estrangeiros ou outros grupos de interesse ${ }^{7}$ (ver Mainwaring et alii, 2001).

Adicionalmente, utilizo aqui uma definição "negativa" de consolidação: um regime político pode ser considerado consolidado após vinte anos de existência sem que suas características básicas sejam transformadas, seja de forma abrupta e violenta ou por meio de uma ero- 
são mais ou menos lenta e relativamente pacífica. Os problemas típicos da transição de um regime político para outro são importantes em si mesmos, mas também são relevantes porque condicionam o desenho institucional e o desempenho do novo regime político (Aguero, $1998)^{8}$.

Além do problema da "durabilidade", uma agenda de pesquisa normativamente orientada a respeito dos regimes políticos gira, necessariamente, em torno da pergunta sobre "que diferença faz" ter um ou outro tipo de regime político para a liberdade e a igualdade dos membros individuais de uma sociedade. No caso em tela, saber se um regime político é democrático necessariamente envolve avaliar a consistência entre o regime político e áreas específicas de atuação governamental. Parte significativa do esforço realizado neste texto tem por objetivo justamente estabelecer parâmetros para testes comparativos de consistência desse tipo na área de segurança estatal em geral, e na área de inteligência em particular 9

\section{O Brasil como Democracia Consolidada: Medidas Comportamentais Agregadas}

Com base nas três primeiras características utilizadas como critérios de classificação (eleições competitivas, sufrágio universal e vigência de liberdades políticas e civis), há amplo consenso na literatura sobre a natureza democrática do atual regime político brasileiro. Esta conclusão geral aparece em projetos de pesquisa que usam classificações dicotômicas que dividem os regimes políticos em democracias ou ditaduras (e.g. Przeworski et alii, 2000), bem como em classificações tricotômicas que incluem algum tipo de semidemocracia ou semi-autoritarismo como forma de acomodar violações parciais de um ou mais critérios adotados (Mainwaring et alii, 2001). Do mesmo modo, isso também ocorre em projetos que usam medidas contínuas de democracia, tais como o Projeto Polity da Universidade de Maryland ou o índice da fundação Freedom House, nos quais o Brasil recebe avaliações que o consideram democrático ${ }^{10}$.

Na última classificação da Freedom House (2004), por exemplo, o Brasil foi considerado livre, enquanto Venezuela e Colômbia foram classificadas como parcialmente livres. Note-se que estes dois países foram incluídos na amostra de casos do ambicioso estudo comparativo de Arend Lijphart (2003) sobre a relação entre tipos de regimes de- 
mocráticos e desempenho econômico, social e político dos países, sendo que tal inclusão se deu justamente porque ambos os países andinos atendiam naquele momento ao duplo requisito adotado pelo autor para aceitar um regime democrático como consolidado: durar mais de vinte anos sem rupturas institucionais e ser classificado como plenamente livre pela Freedom House ${ }^{11}$.

Embora a duração do regime democrático brasileiro ainda não tenha superado esse limiar de vinte anos de estabilidade, quer se considere o ano da transferência de poder dos militares para um presidente civil (1985), quer se considere o ano da primeira eleição direta para a Presidência da República sob uma Constituição democrática (1989), o país encontra-se agora muito próximo de atender a esse requisito. Além disso, todas as avaliações internacionais prospectivas de risco político para um período de cinco anos são consistentes, há vários anos, em afirmar que não se vislumbra, no caso do Brasil, a possibilidade de uma interrupção do processo democrático (Kingstone e Power, $2000)^{12}$.

Finalmente, a eleição do presidente Lula no final de 2002 e a chegada do Partido dos Trabalhadores - PT ao governo federal têm sido destacadas como evidências de consolidação da democracia brasileira. Creio que isso faz sentido, tanto por razões políticas quanto sociológicas. Em termos políticos, a situação de "governo dividido" que caracteriza a cena brasileira, com a oposição controlando os governos estaduais mais importantes e o presidente dispondo de maioria precária no Congresso, exige que a coalizão governante imprima alguma marca própria na priorização de gastos públicos até o final do mandato de Lula em 2006. Em termos sociológicos, a coalizão de Lula implicou uma circulação das elites na gestão pública e nos cargos representativos da República maior do que a observada em qualquer outro governo federal desde o final do regime militar ${ }^{13}$.

Em resumo, segundo medidas comportamentais agregadas e critérios de classificação minimalistas, o regime político brasileiro é considerado democrático e consolidado ${ }^{14}$.

Entretanto, uma avaliação mais completa do desempenho "qualitativo" do regime político vigente no Brasil demanda uma discussão mais detida sobre o exercício da quarta condição mencionada no início desta seção. Para fins de comparação posterior com outros países, 
utilizarei três conjuntos de observações adicionais no caso do Brasil: 1) medidas estruturais de desempenho no provimento de eqüidade (renda per capita nominal e índice de desigualdade social) e medidas atitudinais (satisfação com a democracia e apoio da população a esta forma de governo), contrastadas com um "limiar de estabilização" previamente estabelecido; 2) o estado atual das relações civil-militares no país; 3 ) indicadores de capacidade estatal. Os problemas relativos ao uso de tais medidas serão discutidos ao longo do texto.

\section{O Brasil como Democracia ainda Vulnerável: Déficits Estruturais e Atitudes}

Adotarei aqui os limiares propostos por Andreas Schedler (2001a) para três indicadores não comportamentais de qualidade democrática, a saber: renda per capita nominal superior a US\$3.000, desigualdade inferior a 0,50 (coeficiente de Gini) e legitimidade acima de $66 \%$ (apoio declarado ao regime democrático). Os três limiares são relativamente baixos e assumidamente arbitrários, servindo, no entanto, ao propósito de fornecer um parâmetro comparativo mínimo.

Em relação aos fundamentos socioeconômicos, o Brasil tinha US\$ 2.993 de renda per capita nominal na média dos anos 1999-2003. Uma vez ajustada pela paridade do poder de compra, esta renda per capita estava estimada em US\$7.600 em 2003, mas sem melhorias significativas há muitos anos. Além disso, essa renda média oculta uma altíssima concentração, com os $10 \%$ mais ricos controlando quase metade da renda familiar e com disparidades muito grandes inclusive dentro desse decil de renda mais elevado. Ostentando um coeficiente de Gini de 0,59 em 1999 e um Índice de Desenvolvimento Humano de 0,750 em 2001, o Brasil apresenta ainda significativas e persistentes desigualdades raciais, de gênero e regionais (maior parte do PIB gerado nas regiões Sudeste e Sul), bem como clivagens determinadas por diferentes graus de controle sobre recursos cruciais (terra, crédito, tecnologias de comunicação e informação, escolarização etc.).

Por sua vez, em relação aos fundamentos atitudinais dos comportamentos dos atores, os dados da pesquisa de opinião Latinobarómetro para 2004 indicam que apenas $4 \%$ dos entrevistados no Brasil confiam nas outras pessoas. Este baixíssimo índice de confiança interpessoal é consistente com o número decrescente de pessoas que apóiam consis- 
tentemente a democracia como regime de governo (queda de $9 \%$ desde 1996). Dados da mesma pesquisa indicam que somente $28 \%$ dos entrevistados brasileiros estão satisfeitos com a democracia, enquanto apenas $41 \%$ consideram esta forma de governo superior a qualquer outra (sendo que este percentual chega a $74 \%$ no caso da Venezuela e, no caso do Uruguai, a 78\%). Somente $56 \%$ dos entrevistados afirmam que não apoiariam um golpe militar em nenhuma condição; apenas $46 \%$ acreditam que um governo militar solucionaria menos coisas que um governo democrático, embora apenas 18\% declarem acreditar que em algumas circunstâncias um governo autoritário seria preferível a um governo democrático. Em 2001, 53\% dos entrevistados brasileiros confiavam nas Forças Armadas (contra uma média de $38 \%$ na América Latina), enquanto as instituições representativas brasileiras contavam com taxas de apoio abaixo da média para a América Latina (cujas médias eram de $24 \%$ no caso dos parlamentos, $19 \%$ para os partidos políticos e $30 \%$ para os presidentes) (Latinobarómetro, 2004; ver, também, Dominguez e Shifter, 2003:137-161).

Ou seja, o Brasil apresenta índices piores em medidas estruturais e atitudinais de desempenho do que nas medidas comportamentais agregadas. Com todas as dificuldades metodológicas (e.g. mensuração e validade de indicadores atitudinais) e teóricas (e.g. direção da causalidade) que possam ser lembradas, o fato é que tanto os condicionantes estruturais (condições socioeconômicas) quanto os fundamentos atitudinais (valores, opiniões e preferências) dos comportamentos dos sujeitos políticos indicam que a "consolidação" - no sentido negativo adotado - do regime democrático brasileiro está longe de significar o fim das vulnerabilidades ou um desempenho excelente do regime ao longo dos últimos quinze anos.

Trata-se de um problema comum a todas as "novas democracias" em maior ou menor grau, mas a aposta dos estudiosos e dos policymakers é que tais problemas possam ser revertidos ou minimizados a partir de investimentos pesados em reforma institucional, ainda que demorados e incertos. Utilizando uma imagem de três estágios no processo de desenvolvimento latino-americano posterior a 1990, Patrice Franko (2003:490-494) conclui que, mesmo nos casos de superação bem-sucedida do primeiro estágio ("estabilização severa" dos fundamentos macroeconômicos), ou mesmo do segundo estágio de desenvolvimento ("transformação estrutural" dos equilíbrios entre Estado/mercado e interno/externo), os desafios associados ao terceiro 
estágio ("construção de capacidades") seriam justamente os mais demorados e difíceis, envolvendo investimentos significativos e sustentados ao longo do tempo em desenvolvimento humano, melhoria de produtividade, infra-estrutura e mudança nos padrões de interação entre indivíduos, grupos e instituições formais e informais ${ }^{15}$.

Nesse sentido, a aposta na reforma das instituições, a segunda direção em que o desempenho do regime político brasileiro precisa ser melhor analisado, em conexão com os desafios na área de inteligência, diz respeito exatamente aos aspectos institucionais que seriam mais ou menos conducentes a uma estruturação ágil e legítima desses serviços. Tais aspectos institucionais, por sua vez, podem ser divididos, adicionalmente, em dois tipos de considerações: primeiro, o equacionamento das relações civil-militares nos marcos de um regime democrático caracterizado por forte viés consensual na moldura institucional mais ampla e por problemas estruturais e atitudinais que persistem após a consolidação democrática; segundo, o problema da capacidade estatal em um país semiperiférico nos marcos de uma transição sistêmica de poder no plano global ${ }^{16}$.

\section{Relações Civil-Militares como Medida de Desempenho Democrático}

Identificar padrões de relações civil-militares é tarefa decisiva para que se possa avaliar um regime político democrático. $\mathrm{Na}$ área de inteligência isto é ainda mais importante, uma vez que na maioria dos países as Forças Armadas e os Ministérios da Defesa controlam a maior parte dos recursos orçamentários, humanos, tecnológicos e organizacionais que o Estado tenha sido capaz de acumular na área de inteligência (Antunes e Cepik, 2003). No caso das "novas democracias" com menos de vinte anos, há uma razão adicional decorrente da grande presença de militares da reserva e da ativa nos escalões intermediários e superiores das agências civis de inteligência. Em termos analíticos mais gerais, supõe-se então que o estado das relações civil-militares em um dado país tende a ser consistente com o regime político vigente. Além disso, as relações civil-militares são um indicador indireto do grau de controle democrático sobre os serviços de inteligência ${ }^{17}$.

Como lembra Rojas (2004:1-11), entre 1990 e 2004, a América Latina vivenciou pelo menos cinco golpes de Estado, vinte rebeliões e / ou sé- 
rias crises militares, além de oito colapsos/derrubadas de governos. Em alerta semelhante, Trinkunas (2000:78) destaca que, ao longo dos últimos quinze anos, houve no mundo todo um número significativo de transições da democracia para regimes autoritários (apenas entre 1990 e 1992 houve doze golpes de Estado bem-sucedidos e 26 fracassados).

Como os padrões de relacionamento entre civis e militares que estão emergindo nas novas democracias são tão complexos e diversificados quanto os próprios regimes políticos democráticos, é preciso utilizar como ponto de partida para a análise um modelo que reconheça essa diversidade tipológica e também seja sensível à variação temporal. Embora existam várias alternativas que correspondem a esse duplo requisito, adotarei aqui a perspectiva proposta por Samuel Fitch $(1998)^{18}$.

Segundo Fitch (idem:36-60), sistemas democráticos de relações civil-militares possuem três características essenciais: 1) existe uma clara subordinação das Forças Armadas ao processo decisório democrático, com a superação da noção autoritária de que as Forças Armadas são as "guardiãs da nação", situadas acima da soberania popular e das instituições representativas de governo que decidem concretamente quais são os "interesses nacionais" nos marcos de uma Constituição livremente adotada; 2) verifica-se a subordinação das cadeias de comando e controle das Forças Armadas às autoridades civis designadas constitucionalmente para implementar as políticas públicas de defesa e segurança; 3 ) os militares estão sujeitos ao império da lei (rule of law), tanto no sentido de não terem quaisquer direitos constitucionais ordinários negados (como em alguns países que proíbem os militares de votar), quanto no sentido de não terem privilégios legais e isenções de responsabilidade por atos cometidos no exercício de suas funções profissionais.

Avaliando a experiência dos países latino-americanos depois de 1990, é possível identificar pelo menos dois padrões diferentes de profissionalização ("clássico-huntingtoniano" e "desenvolvimentista"), quatro níveis de "autonomia para governar depois de eleito" (ditadura militar, tutela das Forças Armadas sobre o governo, subordinação condicional e controle democrático) e um continuum discreto de situações mais ou menos institucionalizadas para os dois padrões e os quatro níveis. As duas situações intermediárias (tutela militar e subordi- 
nação condicional) apresentam diferenças de grau e podem ocorrer tanto em regimes democráticos quanto autoritários ${ }^{19}$. A diferença principal entre ambas é que, no caso da tutela militar, o poder de veto e a influência exercida pelos militares nas decisões políticas são "expansivos", abarcando temas da vida política muito além da área de defesa, tais como conflitos distributivos, legislação previdenciária, posse de terra, política ambiental, duração de mandatos presidenciais etc. No caso da subordinação condicional, as Forças Armadas operam como um dos grupos de interesse poderosos na sociedade e subordinam-se aos governantes na maioria dos casos, desde que interesses vitais da corporação não sejam contrariados. Mesmo quando as Forças Armadas aderem às regras constitucionais, deixam de considerar a si próprias como guardiãs dos "objetivos nacionais permanentes" e subordinam-se às decisões governamentais sobre política de defesa e estrutura das forças. A debilidade dos mecanismos de controle democrático existentes no Legislativo e Executivo pode implicar margens significativas de autonomia em termos de doutrina, organização, prioridades de investimento, gestão de pessoal, inteligência etc.

Na Figura 1, encontra-se uma adaptação do argumento de Fitch (1998:39), que enfatiza os dois atributos fundamentais e sua evolução ao longo do tempo. Embora haja significativa controvérsia sobre o grau de autonomia militar no Brasil pós-1990, a maioria dos pesquisadores concorda que as relações civil-militares durante o primeiro governo democrático após a transição (1985-1989) foram caracterizadas por tutela militar (assim como no caso do Chile), enquanto o período entre 1990 e 1999 foi marcado por uma evolução lenta para níveis de subordinação condicional cada vez menos severos, especialmente nos anos após a criação do Ministério da Defesa (2000-2004).

Entretanto, nem mesmo os analistas mais otimistas em relação aos casos do Brasil, ou mesmo da Argentina e do Uruguai, chegam a afirmar que estes países hoje possuem sistemas de controle democrático plenamente institucionalizados sobre as Forças Armadas. A razão principal para esta relutância, especialmente no caso brasileiro, é a extrema fragilidade institucional do novo Ministério da Defesa vis-à-vis os comandos das três forças, bem como a falta de assertividade das comissões parlamentares permanentes e do Congresso brasileiro como um todo no exercício de suas capacidades de supervisão e influência sobre prioridades, tanto políticas quanto orçamentárias ${ }^{20}$. 
Figura 1

Padrões de Relação Civil-Militar segundo Fitch (1998)

Militares exercem poder de veto em temas não-militares

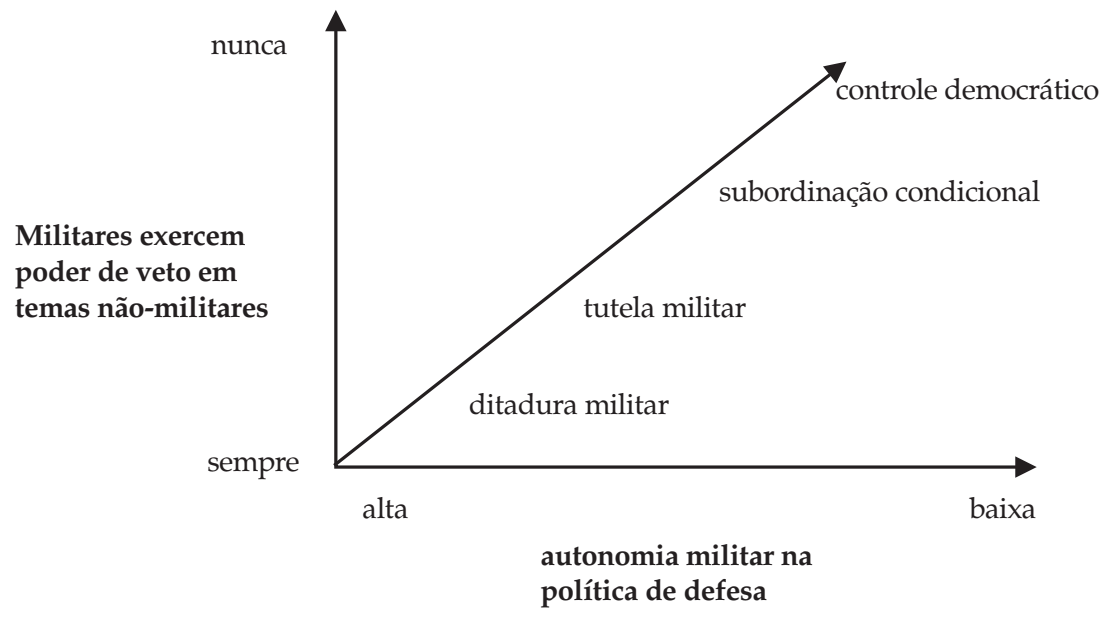

Portanto, assim como no caso dos "limiares de consolidação" das variáveis estruturais e atitudinais discutidas na seção anterior, pode-se dizer que, em termos de relações civil-militares, o Brasil se encontra atualmente em um patamar intermediário, entre o que Fitch caracteriza como subordinação condicional e uma situação mais claramente identificável como "controle democrático". Aceito provisoriamente esta avaliação, reconhecendo que ela é imprecisa e subjetiva. E aceitá-la tem pelo menos duas implicações para a discussão sobre os serviços de inteligência.

Em primeiro lugar, indica que o grau de controle democrático exercido sobre os serviços de inteligência militares é baixo e que isso tem conseqüências para o desempenho do regime democrático brasileiro. A matriz formulada por Peter Gill (1994:82) para classificar serviços de inteligência em função de graus de legitimidade derivados da observação de duas dimensões (autonomia decisória e pervasividade na sociedade) e três níveis (alto, médio e baixo), em princípio, fornece nove possibilidades de classificação capazes de distinguir não apenas a situação de distintos serviços de inteligência e de segurança de um mesmo país em um mesmo momento histórico, mas também de um mesmo serviço em diferentes momentos históricos, ou ainda permite a classificação de sistemas nacionais de inteligência para todos os países que contam com este tipo de agência governamental. Uma primeira tentativa de classificar as organizações brasileiras segundo 
essa matriz será feita na seção final deste texto. Vale notar desde já, entretanto, que as proposições de Fitch (1998) e Gill (1994) são compatíveis e úteis para um enquadramento comparativo dos serviços de inteligência, embora ambas tenham como foco principal os problemas de legitimidade, mais do que os problemas de efetividade.

Em segundo lugar, portanto, o nexo entre relações civil-militares e controle democrático dos serviços de inteligência conduz à discussão sobre capacidade estatal. No contexto atual da América Latina, onde as limitações orçamentárias se tornaram cada vez mais dramáticas ao longo da última década, ao mesmo tempo que houve pressões internas e externas para ampliar o envolvimento das Forças Armadas e dos serviços de inteligência em áreas cada vez mais afastadas da política internacional e das missões de defesa do território contra ameaças externas, o envolvimento dessas organizações em missões cívicas, antinarcóticos, de provimento de ordem pública e tantas outras, sem um adequado desenvolvimento de equipamento, organização e doutrina, tende a trazer de volta para a agenda do controle democrático os temas tradicionais associados ao binômio "segurança e desenvolvimento" das décadas de 60 e 70.

\section{Capacidade Estatal e Democracia: Tributação e Defesa como Indicadores}

A capacidade de formulação, implementação e avaliação de políticas públicas de um Estado é uma dimensão inseparável da avaliação da qualidade da democracia. Sem uma adequada capacidade institucional de fazer valer as regras e implementar as decisões tomadas pelos sujeitos políticos, ou sem a capacidade de garantir o cumprimento dos direitos e deveres associados à cidadania, um regime democrático torna-se aquilo que os cientistas políticos da República de Weimar chamariam de "um pacto suicida". Por isso, a literatura de política comparada vem enfatizando, há mais de dez anos, o estudo dos dilemas associados à construção de capacidades institucionais e fortalecimento do Estado (Geddes, 1994).

Entretanto, na maioria dos casos, os estudos disponíveis estão voltados para a relação entre eficiência e legitimidade nas áreas de política econômica e/ ou políticas sociais. Faltam estudos similares no âmbito da defesa, segurança pública e inteligência. Como os Estados contemporâneos são definidos (e diferenciados entre si) pela sua capacidade 
de prover segurança e bem-estar a todos os cidadãos, ainda que os gastos públicos de todos os países mais importantes no sistema internacional sejam predominantemente gastos sociais (saúde, educação, pensões e outras políticas sociais) e não mais gastos militares, isso não torna menos relevante o desempenho do Estado na área de segurança para uma avaliação das condições de consolidação democrática (Lane e Ersson, 1994).

Um bom exemplo de como as duas dimensões podem ser integradas aparece na Figura 2, onde é possível visualizar a formulação recente de Charles Tilly (2003:41) sobre a variação concomitante dos regimes políticos em termos de capacidade do Estado e de aprofundamento da democracia.

É importante notar, sobretudo, como o modelo assume que existem áreas de autoritarismo mesmo em regimes políticos caracterizados por alta capacidade governamental e democracia. Estas "zonas de autoritarismo" caracterizam não apenas os países mais industrializados da semiperiferia (e.g. Brasil e África do Sul), mas também certas áreas de atuação e atividades do Poder Executivo dos países centrais onde os mecanismos de controle democrático são precários ou enfrentam dificuldades significativas (e.g. atividades de inteligência e opera-

Figura 2

Capacidade Governamental e Democracia em Charles Tilly (2003)

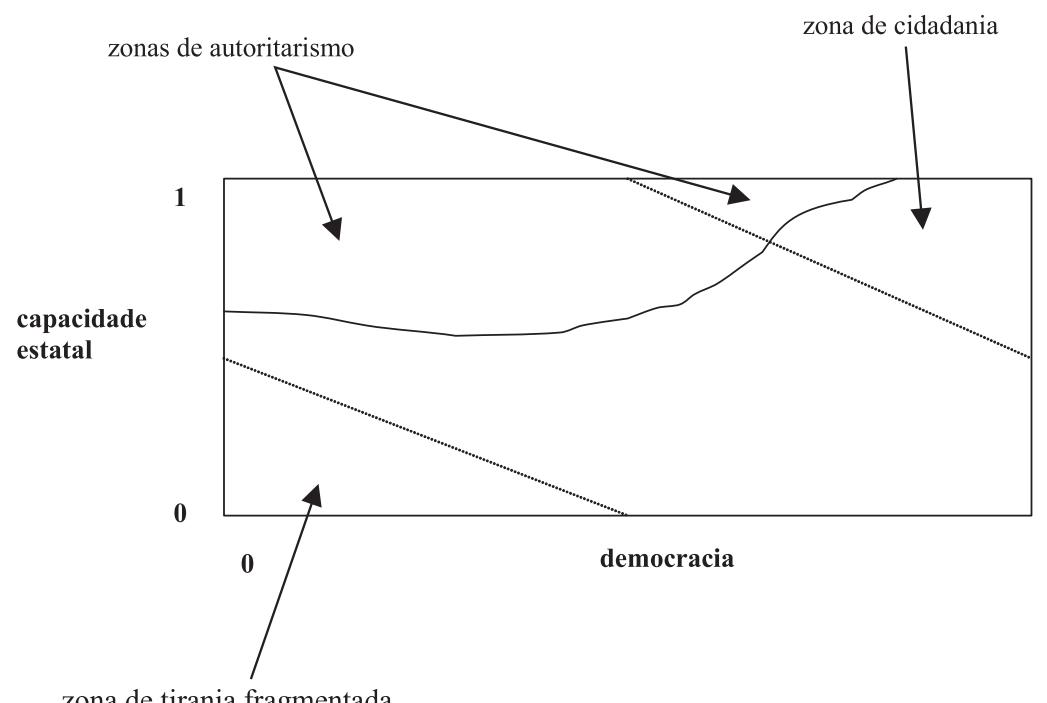

zona de tirania fragmentada 
ções militares). Além disso, mostra como a relação entre legitimidade e efetividade é complementar e não antagônica. O que Tilly (2003) chama de "zona de cidadania" traduz, simultaneamente, o que Dahl (1997) chamou de "poliarquia" (enfatizando o grau de democracia) e o que Huntington (1975) chamou de "comunidade cívica" (enfatizando o grau de governo). Em outras palavras, descreve os traços ideaistípicos de um regime político onde há grande quantidade de poder acumulado e um nível mínimo de distribuição desse poder entre os indivíduos e grupos sociais relevantes para a sustenção do regime.

Existe grande divergência sobre medidas internacionalmente comparáveis de capacidade governamental agregada. Deixando de lado, por ora, uma possível utilização de medidas de capacidade disponíveis na área de políticas sociais adaptáveis para as áreas de defesa, segurança e inteligência, neste texto vou utilizar como proxy genérica de capacidade dos governos a sua capacidade de arrecadar tributos da sociedade e alguns indicadores muito subjetivos de capacidade bélica. Para relembrar o sentido do exercício, supõe-se como hipótese de trabalho que a capacidade estatal brasileira seja hoje desproporcionalmente inferior ao grau de democracia observado no país, o que é algo deletério para a "durabilidade" e a "qualidade" do regime democrático no país, demandando assim cuidadosa construção institucional de capacidades específicas que permitam equalizar melhor as duas dimensões ${ }^{21}$.

Para evitar as oscilações anuais características das economias em desenvolvimento e da América Latina em particular nos últimos anos, considere-se o desempenho do Brasil em dois períodos de cinco anos. Naquele de 1994-1998, para um PIB nominal médio de US\$724,11 bilhões, a carga tributária bruta média foi de US\$189,61 bilhões $(26,2 \%$ do PIB). Para o período 1999-2003, o PIB nominal médio caiu para US\$ 520,17 bilhões por ano, mas a carga tributária bruta média naqueles anos subiu para US $\$ 255,88$ bilhões ao ano (49,2\% do PIB). Não obstante essa brutal concentração de recursos nas mãos do Estado, a capacidade de investir ou mesmo de custear as operações correntes foi sendo cada vez mais comprometida, ao longo do período, pelo peso de uma dívida que passou a representar $41,8 \%$ do PIB na média dos anos 1999-2003. Saldos comerciais anuais em média de US\$ 7,7 bilhões (US\$24,82 bilhões em 2003) e saldos primários (receitas menos despesas antes do pagamento de obrigações financeiras e títulos da dívida) crescentes tendem a produzir efeitos positivos a médio prazo, 
mas de modo geral o Estado brasileiro ainda está estrangulado pelo volume e perfil de sua dívida pública no curto prazo ${ }^{22}$.

Um outro indicador relevante para uma avaliação da capacidade do Estado e dos processos de reforma na área de inteligência seria justamente a defesa. Segundo Dunnigan (2003:619-644), o Brasil possuía em 2000 um índice de capacidade de combate terrestre igual a 94, um índice de qualidade total das Forças Armadas de 33\%, cerca de 285.000 efetivos (195.000 no Exército), orçamento de defesa de US\$ 18 bilhões por ano, um gasto militar anual por soldado de US\$ 63, 1.700 veículos blindados, 320 aeronaves de combate dedicadas à guerra terrestre, um índice de capacidade de combate naval igual a 06, representando $0,99 \%$ do poder naval disponível no mundo, com 24 navios de guerra e um índice de qualidade de $65 \%$ para as forças navais. No âmbito do continente americano, a capacidade bélica brasileira estava classificada em segundo lugar depois dos Estados Unidos, sendo o Brasil seguido pelo Canadá, Colômbia, México, Chile, Argentina, Peru, Venezuela, Cuba e então os demais países ${ }^{23}$.

Em relação ao orçamento de defesa, cabe observar que, em função da decisão do governo Lula de aumentar o superávit primário nas contas públicas para reduzir a exposição do país a choques externos (necessidade gerada pela péssima situação econômica herdada do governo Fernando Henrique Cardoso), o volume de recursos aprovados para a área de defesa para o ano fiscal de 2004 foi reduzido em termos nominais em quase $50 \%$ em relação ao ano de 2000, para cerca de US\$ 9,4 bilhões, representando apenas 1,9\% do PIB e também cerca de $1,9 \%$ do orçamento federal de 2004. Entretanto, tão grave quanto a redução global do orçamento de defesa é o perfil dos gastos, com 75,5\% destinados ao pagamento de salários e (principalmente) pensões, $11,3 \%$ para despesas correntes e apenas 3,8\% para investimentos ${ }^{24}$.

Com uma situação orçamentária ainda mais difícil na área de defesa do que na proxy geral representada pela arrecadação tributária, é preciso agora verificar se as mudanças estruturais ocorridas na área de inteligência são consistentes com o tipo de regime político, o grau de democratização e a capacidade estatal brasileira. 


\section{SISTEMA BRASILEIRO DE INTELIGÊNCIA: MUDANÇA ESTRUTURAL E CONTROLE}

Estabelecido o duplo contexto no qual foram realizadas as mudanças estruturais na área de inteligência no Brasil ao longo dos últimos dez anos (consolidação democrática sem redução das desigualdades e baixa capacidade estatal para garantir direitos civis e defesa coletiva), é preciso agora apresentar sistematicamente essas mudanças e refletir sobre os problemas de controle democrático associados à emergência de novas organizações e procedimentos.

\section{Quadro Legal e as Estruturas Organizacionais}

A configuração atual da área de inteligência no Brasil foi estabelecida pela Lei no 9.883, de 7 de dezembro de 1999, por meio da qual o Congresso Nacional criou a Agência Brasileira de Inteligência - ABIN* e instituiu o Sistema Brasileiro de Inteligência - SISBIN.

Legalmente, a ABIN é considerada o órgão central desse sistema e tem a função de regular o fluxo de informações produzidas pelas instituições a ela vinculadas. Com cerca de 1.600 funcionários, a agência contava em 2004 com aproximadamente quatrocentos analistas de informações de nível superior. Na verdade, a Lei no 9.883 continuou uma tradição de definições bastante genéricas acerca do mandato legal das agências de inteligência no Brasil, mas também foi o resultado possível de diversas iniciativas legislativas apresentadas pelos partidos de esquerda e pelo governo Fernando Henrique Cardoso, negociações internas no Poder Executivo e pressões da sociedade civil ao longo da década de $1990^{25}$.

Nos artigos iniciais dessa lei, a atividade de inteligência foi definida como sendo aquela que visa a "obtenção, análise e disseminação de conhecimentos dentro e fora do território nacional sobre fatos e situações de imediata ou potencial influência sobre o processo decisório e a ação governamental e sobre a salvaguarda e a segurança da sociedade e do estado". De maneira igualmente genérica, a contra-inteligência foi enunciada como a "atividade que objetiva neutralizar a inteligência adversa". O conteúdo específico do que seriam as prioridades e ênfases temáticas de ambas as atividades ficou de ser detalhado

\footnotetext{
* Ver Glossário no final deste artigo.
} 
por uma Política Nacional de Inteligência a ser fixada pelo presidente da República, depois de ouvir sugestões do órgão externo de controle no Congresso.

Inicialmente de maneira lenta, mas adquirindo um tempo crescente nos últimos dois anos, emergiu no Brasil uma importante estrutura legal de regulamentação da atividade de inteligência. Para uma visão mais abrangente e rigorosa dessa moldura legal seria preciso analisar de modo integrado a Constituição Federal de 1988, a legislação em vigor diretamente relacionada com os serviços de inteligência e o restante da legislação infraconstitucional que define os crimes contra a segurança do Estado e dos indivíduos, regula os instrumentos de controle do crime (inclusive interceptações telefônicas), define segurança informacional e segredo governamental, fixa os procedimentos de controle para a administração pública de modo geral etc. Obviamente, uma avaliação tão abrangente do quadro legal está muito além das possibilidades deste texto.

É preciso destacar, no entanto, que uma série de decretos e portarias administrativas do Poder Executivo (e.g. o decreto que regulamentou em 2002 o funcionamento do SISBIN), bem como algumas leis específicas (e.g. plano de carreira para os analistas de informações da ABIN, aprovado em 2004), definiram os contornos da atividade de inteligência no âmbito do governo federal. Mesmo considerando que diferentes organizações e/ou funções do sistema brasileiro de inteligência recebem mais ou menos atenção nos regulamentos, pode-se dizer que hoje em dia o Brasil conta com uma legislação bastante desenvolvida nas áreas de inteligência e de segurança informacional (ver Quadro 1 para uma relação dos principais instrumentos) ${ }^{26}$.

Em relação às mudanças organizacionais mais importantes ocorridas depois da criação da ABIN em 1999, é importante destacar pelo menos cinco transformações recentes: a) subordinação da agência ao Gabinete de Segurança Institucional - GSI da Presidência da República; b) criação da Comissão Mista de Controle das Atividades de Inteligência - CCAI no Congresso; c) regulamentação da participação dos ministérios no âmbito do SISBIN; d) criação do Sistema de Inteligência de Defesa-SINDE; e) criação do Subsistema de Inteligência de Segurança Pública - SISP. 
No caso da subordinação da ABIN ao GSI, embora isto signifique uma distorção em relação ao espírito da lei de 1999 (uma vez que o diretor da ABIN é um civil que precisa ter seu nome aprovado pelo Senado e o ministro-chefe do GSI é um general indicado pelo presidente da República), o governo procurou justificar essa decisão, tomada ainda durante o segundo mandato presidencial de Fernando Henrique Cardoso, pela necessidade de preservar o presidente das demandas gerenciais cotidianas e de crises potenciais decorrentes de escândalos e/ou de tensões inerentes à relação entre inteligência e democracia. Na prática, o movimento correspondeu a uma série de responsabilidades que o GSI foi assumindo ao longo do período em função da confiança que o presidente depositava no general Alberto Cardoso (nenhum parentesco com o presidente). O GSI transformou-se no principal instrumento agregador dos fluxos informacionais vindos de vários órgãos federais e no locus de gestão de crises nas áreas de segurança interna e externa. Embora a ABIN seja definida legalmente como o órgão central do sistema e exerça um papel de primus inter pares, na prática sua subordinação ao GSI aumentou o poder de agenda da Presidência da República sobre as prioridades do trabalho de obtenção e análise de informações, ao mesmo tempo que reduziu a autoridade da ABIN sobre os demais órgãos participantes.

\section{Quadro 1}

Legislação Brasileira Relevante para a Área de Inteligência

\begin{tabular}{|c|c|c|c|c|}
\hline $\begin{array}{c}\text { Tipo de } \\
\text { legislação }\end{array}$ & Número & $\begin{array}{c}\text { Ano da } \\
\text { aprovação }\end{array}$ & $\begin{array}{c}\text { Disposições } \\
\text { principais }\end{array}$ & Observações \\
\hline $\begin{array}{c}\text { Constituição } \\
\text { Federal }\end{array}$ & Art. 5 & 1988 & $\begin{array}{c}\text { liberdade de } \\
\text { expressão e direito } \\
\text { à informação }\end{array}$ & $\begin{array}{c}\text { exceções } \\
\text { decorrentes de } \\
\text { segurança do } \\
\text { Estado }\end{array}$ \\
\hline $\begin{array}{c}\text { Constituição } \\
\text { Federal }\end{array}$ & Art. 142 & 1988 & $\begin{array}{c}\text { missões das Forças } \\
\text { Armadas }\end{array}$ & $\begin{array}{c}\text { defesa externa, } \\
\text { garantia da lei e da } \\
\text { ordem, defesa da } \\
\text { Constituição }\end{array}$ \\
\hline Ordinária & 7.170 & 1983 & $\begin{array}{c}\text { Lei de Segurança } \\
\text { Nacional }\end{array}$ & $\begin{array}{c}\text { ainda em vigor. Ver } \\
\text { Projeto de Lei } \\
\text { 6.764/2002 sobre } \\
\text { crimes contra o } \\
\text { Estado e a } \\
\text { democracia }\end{array}$ \\
\hline
\end{tabular}

(continua) 
Regime Político e Sistema de Inteligência no Brasil...

Quadro 1

Legislação Brasileira Relevante para a Área de Inteligência (continuação)

\begin{tabular}{|c|c|c|c|c|}
\hline $\begin{array}{c}\text { Tipo de } \\
\text { legislação }\end{array}$ & Número & $\begin{array}{c}\text { Ano da } \\
\text { aprovação }\end{array}$ & $\begin{array}{c}\text { Disposições } \\
\text { principais }\end{array}$ & Observações \\
\hline $\begin{array}{c}\text { Lei } \\
\text { Ordinária }\end{array}$ & 8.028 & 1990 & $\begin{array}{l}\text { extingue o Serviço } \\
\text { Nacional de } \\
\text { Informações - SNI }\end{array}$ & $\begin{array}{c}\text { superada por novas } \\
\text { disposições ao } \\
\text { longo dos últimos } \\
\text { quinze anos }\end{array}$ \\
\hline $\begin{array}{c}\text { Lei } \\
\text { Ordinária }\end{array}$ & 8.159 & 1991 & $\begin{array}{c}\text { política nacional de } \\
\text { arquivos }\end{array}$ & $\begin{array}{l}\text { regula acesso às } \\
\text { informações } \\
\text { governamentais }\end{array}$ \\
\hline $\begin{array}{c}\text { Decreto } \\
\text { Executivo }\end{array}$ & 4.553 & 2002 & $\begin{array}{c}\text { regulamenta } \\
\text { segurança } \\
\text { informacional }\end{array}$ & $\begin{array}{l}\text { classificações de } \\
\text { segurança e } \\
\text { credenciais de } \\
\text { acesso }\end{array}$ \\
\hline $\begin{array}{c}\text { Lei } \\
\text { Ordinária }\end{array}$ & 9.034 & 1995 & $\begin{array}{c}\text { uso de meios } \\
\text { operacionais para } \\
\text { prevenção e } \\
\text { repressão ao crime }\end{array}$ & $\begin{array}{l}\text { alguns artigos } \\
\text { alterados pela lei } \\
10.217 / 2001\end{array}$ \\
\hline $\begin{array}{c}\text { Lei } \\
\text { Ordinária }\end{array}$ & 9.296 & 1996 & $\begin{array}{c}\text { autorização judicial } \\
\text { para interceptação } \\
\text { telefônica }\end{array}$ & $\begin{array}{l}\text { ABIN não pode } \\
\text { solicitar ou } \\
\text { executar }\end{array}$ \\
\hline $\begin{array}{c}\text { Lei } \\
\text { Ordinária }\end{array}$ & 9.883 & 1999 & $\begin{array}{c}\text { cria a ABIN e o } \\
\text { SISBIN }\end{array}$ & $\begin{array}{c}\text { define missões, } \\
\text { genericamente, nas } \\
\text { áreas de obtenção e } \\
\text { análise de } \\
\text { inteligência e } \\
\text { contra-inteligência }\end{array}$ \\
\hline $\begin{array}{l}\text { Lei } \\
\text { Complemen- } \\
\text { tar }\end{array}$ & 97 & 1999 & $\begin{array}{c}\text { cria o Ministério da } \\
\text { Defesa - MD e o } \\
\text { Estado-Maior de } \\
\text { Defesa - EMD }\end{array}$ & $\begin{array}{c}\text { estrutura do MD foi } \\
\text { detalhada pelo } \\
\text { Decreto } 4.735 / 2003 \\
\text { e pela Portaria MD } \\
1.037 / 2003\end{array}$ \\
\hline $\begin{array}{l}\text { Decreto } \\
\text { Executivo }\end{array}$ & 3.695 & 2000 & $\begin{array}{l}\text { institui } \\
\text { o SISP }\end{array}$ & $\begin{array}{l}\text { SENASP / MJ como } \\
\text { órgão central; } \\
\text { corrige a versão } \\
\text { inicial do decreto } \\
3.348 / 2002 \text { que } \\
\text { havia definido a } \\
\text { ABIN como centro } \\
\text { do SISP }\end{array}$ \\
\hline
\end{tabular}

(continua) 
Quadro 1

Legislação Brasileira Relevante para a Área de Inteligência (continuação)

\begin{tabular}{|c|c|c|c|c|}
\hline $\begin{array}{c}\text { Tipo de } \\
\text { legislação }\end{array}$ & Número & $\begin{array}{c}\text { Ano da } \\
\text { aprovação }\end{array}$ & $\begin{array}{c}\text { Disposições } \\
\text { principais }\end{array}$ & Observações \\
\hline $\begin{array}{c}\text { Decreto } \\
\text { Executivo }\end{array}$ & 4.376 & 2002 & $\begin{array}{c}\text { detalha } \\
\text { organização do } \\
\text { SISBIN }\end{array}$ & $\begin{array}{c}\text { define membros do } \\
\text { SisBiN e do } \\
\text { Conselho } \\
\text { Consultivo, } \\
\text { complementado } \\
\text { pelo decreto } \\
4.872 / 2003\end{array}$ \\
\hline $\begin{array}{c}\text { Portaria } \\
\text { Ministério } \\
\text { da Defesa }\end{array}$ & 295 & 2002 & institui o SINDE & $\begin{array}{l}\text { Departamento de } \\
\text { Inteligência } \\
\text { Estratégica - DIE } \\
\text { do MD como órgão } \\
\text { central }\end{array}$ \\
\hline $\begin{array}{c}\text { Lei } \\
\text { Ordinária }\end{array}$ & 10.862 & 2004 & $\begin{array}{l}\text { plano especial de } \\
\text { cargos da ABIN }\end{array}$ & $\begin{array}{c}\text { define a carreira de } \\
\text { analista de } \\
\text { informações de } \\
\text { nível superior e } \\
\text { detalha formas de } \\
\text { ingresso, } \\
\text { treinamento, } \\
\text { progressão e } \\
\text { aposentadoria }\end{array}$ \\
\hline $\begin{array}{l}\text { Projeto de } \\
\text { Resolução } \\
\text { do } \\
\text { Congresso } \\
\text { Nacional }\end{array}$ & 08 & 2000 & CCAI & $\begin{array}{l}\text { CCAI funciona } \\
\text { desde 2000; o } \\
\text { Congresso ainda } \\
\text { não aprovou o } \\
\text { regimento } \\
\text { (fevereiro 2005) }\end{array}$ \\
\hline
\end{tabular}

O segundo desenvolvimento estrutural relevante desde 1999 foi a instalação da CCAI no Congresso Nacional, ocorrida em novembro de 2000. Prevista na Lei no 9.883, de 7 de dezembro de 1999, sob a denominação de Órgão de Controle e Fiscalização Externo, a instalação da Comissão Mista ocorreria apenas um ano mais tarde. Tendo realizado onze reuniões até julho de 2004, a CCAI enfrentou até aqui dificuldades para exercer suas funções de controle, as quais decorrem de três fatores principais: 1ํ) do próprio desenho institucional do órgão, presidido a cada ano em caráter rotativo pelo presidente da Comissão de Relações Exteriores e Defesa Nacional do Senado e da Câmara dos Deputados; $2^{\circ}$ ) da falta de recursos técnicos e de pessoal, como exem- 
plifica o fato de que a única funcionária do Senado que se especializou no tema e contribuiu decisivamente para implementar a CCAI tem que apoiar os trabalhos de várias comissões e da mesa diretora do Senado; 3) da falta de assertividade do Congresso Nacional como um todo no trato com os componentes militares e policiais do SISBIN, uma vez que a ABIN e os demais ministérios não parecem ter colocado maiores obstáculos ao trabalho da comissão ao longo destes primeiros anos.

Por outro lado, a CCAI foi presidida por parlamentares importantes da coalizão de centro-esquerda entre 2000 e 2003, tendo realizado iniciativas conjuntas com órgãos do Poder Executivo, tais como um seminário inédito sobre o tema, transmitido pela TV do Senado e que contou com a presença de palestrantes do Brasil e do exterior, além de mais de trezentos participantes, ou o igualmente inédito processo de consulta à sociedade civil acerca das prioridades da Política Nacional de Inteligência, um processo iniciado em 2003 e ainda em fase de implementação. Apesar destas iniciativas, até fevereiro de 2005 a CCAI não tinha conseguido ainda ver seu regimento interno aprovado pelo Congresso e suas reuniões e atividades esporádicas continuavam sendo excessivamente determinadas por uma lógica reativa a eventuais escândalos e denúncias que aparecem na mídia ${ }^{27}$.

Além da CCAI, outras quatro comissões poderiam exercer algum papel no controle externo sobre diferentes partes do sistema, quais sejam: as Comissões de Relações Exteriores e Defesa Nacional da Câmara - CREDEN e do Senado - CRE, bem como a Comissão de Segurança Pública e Combate ao Crime Organizado - CSPCCO da Câmara dos Deputados e, ainda, a Subcomissão Permanente de Segurança Pública da Comissão de Constituição, Justiça e Cidadania do Senado Federal. Em relação aos orçamentos, exercem fiscalização sobre a área de inteligência tanto a Secretaria de Controle Interno da Presidência da República quanto o Tribunal de Contas da União - $\mathrm{TCU}^{28}$.

A publicação do Decreto Executivo no 4.376, em 2002, representou um passo além na delimitação das fronteiras organizacionais do SISBIN. Da forma como o sistema havia sido definido na lei de 1999, ele não apenas poderia incorporar, mediante convênios, ministérios e órgãos da administração federal indireta, assim como organizações estaduais e municipais, mas até mesmo empresas privadas e entidades da sociedade civil. Embora estes artigos da lei sigam em vigor e tenham 
sido reiterados pelo texto do decreto, na prática, alguma estabilidade organizacional foi obtida, fixando-se as unidades de cada ministério responsáveis pela interação com o SISBIN.

Em 2004, o SISBIN era formado pelo GSI, ABIN, Ministério da Defesa, Ministério das Relações Exteriores, Casa Civil da Presidência da República (órgão responsável pela gestão do Sistema de Proteção da Amazônia), Ministério da Justiça, Ministério da Fazenda, Ministério da Integração Regional, Ministério da Ciência e Tecnologia, Ministério do Meio Ambiente, Ministério da Saúde, Ministério da Previdência Social e, ainda, pelo Ministério do Trabalho. Entretanto, o peso relativo de cada um desses treze componentes principais é bastante distinto.

Como se pode notar na Figura 3, pelo menos dois ministérios participam do SISBIN por meio de três unidades ou mais (Justiça e Defesa), sendo que o Ministério da Fazenda participa por meio da Secretaria da Receita Federal e da unidade de inteligência do Banco Central. O Conselho Consultivo do SISBIN é formado pelo GSI, ABIN, Itamaraty

Figura 3

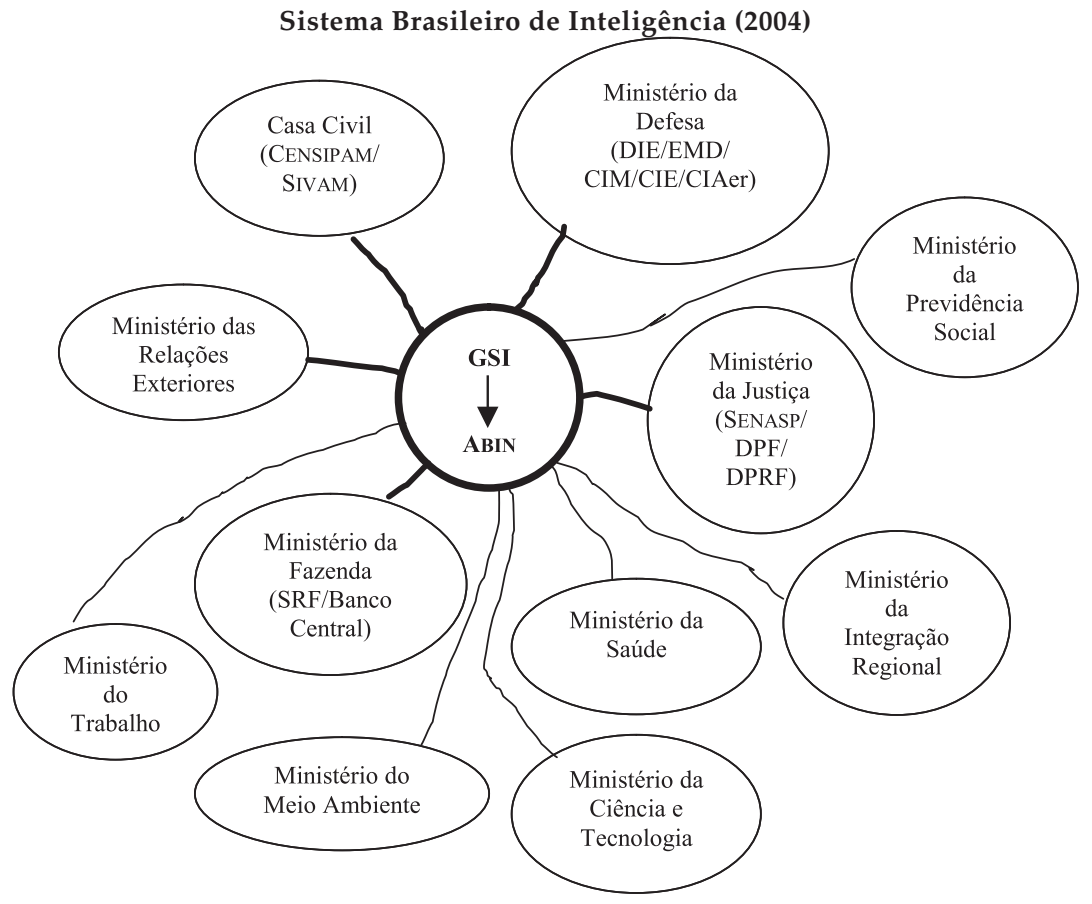


(MRE), Casa Civil, bem como pelos Ministérios da Defesa, da Justiça e da Fazenda. Ao se definir um Conselho Consultivo composto por um número ainda mais limitado de ministérios representados por unidades analíticas e/ou operacionais relevantes para a área de inteligência, procurou-se reforçar a tendência de melhor delimitação organizacional sem perda de especialidades funcionais e/ou temáticas ${ }^{29}$.

Finalmente, é preciso destacar a formalização recente de outras duas redes de inteligência no Brasil: o SISP e o SINDE.

Embora o SISP tenha sido estabelecido em 2000 por meio do Decreto Executivo no 3.695, até agora seu potencial integrador dos fluxos de informação nas áreas de inteligência criminal, inteligência de segurança (ou interna), contra-inteligência e contraterrorismo foi pouco desenvolvido - este subsistema é coordenado pela Secretaria Nacional de Segurança Pública, do Ministério da Justiça. Numa iniciativa sem precedentes, no segundo semestre de 2003, a equipe responsável pela coordenação do SISP realizou importantes esforços para a formulação de uma doutrina de inteligência de segurança pública, bem como para treinar os núcleos gestores do subsistema nos estados e formular de maneira cooperativa as bases de um Plano Nacional de Inteligência de Segurança Pública - PNISP. Infelizmente interrompi$\mathrm{da}$, tal iniciativa era crucial para que o Brasil pudesse enfrentar o crime organizado e a violência urbana, que tendem a transformar-se na pior ameaça à segurança dos cidadãos e do próprio Estado. Os principais componentes operacionais do SISP são: o Departamento de Polícia Federal - DPF e o Departamento de Polícia Rodoviária Federal DPRF, no Ministério da Justiça; COAF, COPEI e SRF, do Ministério da Fazenda; membros do Ministério da Integração Regional, do Ministério da Defesa, do Gabinete de Segurança Institucional da Presidência da República, além das polícias civil e militar dos 26 estados e do Distrito Federal. Embora definido como um subsistema do SISBIN, na prática, a quantidade de organizações envolvidas e a capilaridade das redes de inteligência das polícias tendem a transformar o SISP em um sistema apenas parcialmente integrado ao $\operatorname{SISBIN}^{30}$.

Já o SINDE foi estabelecido formalmente em junho de 2002, por meio de uma medida administrativa do ministro da Defesa (Portaria no 295/MD). Este sistema foi criado para articular os centros de inteligência da Marinha (CIM), Exército (CIE), Aeronáutica (CIAer) e Estado-Maior de Defesa (EMD-2) com o Ministério da Defesa. Daí porque 
a coordenação do SINDE cabe ao Departamento de Inteligência Estratégica desse Ministério (DIE), que também é responsável pela representação do SINDE junto ao SISBIN e ao Congresso Nacional. Estão subordinados ao Ministério de Defesa os serviços de inteligência de cada força, assim como secretarias e chefias responsáveis pela inteligência estratégica e operacional. Em geral, o suporte tático às unidades de escalão intermediário é mais precário do que a capacidade central em cada força singular ${ }^{31}$.

Apesar da nomenclatura utilizada (a idéia funcionalista de sistema), o grau de centralização hierárquica ou mesmo de equilíbrio homeostático no SisBiN é baixo. Afinal, a noção de "sistema" remete justamente à idéia de um todo que é mantido coeso pela diferenciação funcional de suas partes. No caso dos três sistemas de inteligência brasileiros, pode-se dizer que o grau de diferenciação funcional do sistema é baixo, o que contribui para tornar toda a iniciativa de integração um ato de "cooperação voluntária" entre agências que competem por recursos muito escassos. O estabelecimento formal do SISBIN, do SISP e do SINDE significa um passo significativo para gerar cooperação entre as agências e, no melhor dos mundos possíveis, melhorar a integração de fluxos informacionais vitais para a segurança do Estado e dos cidadãos, mas é apenas um passo no que parece ser ainda um longo caminho no processo de institucionalização ${ }^{32}$.

\section{Prioridades, Políticas e ênfases dos dois Últimos Governos}

Por outro lado, os novos "sistemas" na área de inteligência no Brasil contribuem para simplificar os procedimentos de controle externo sobre a atividade, na medida em que criam pontos de interação mais focalizados entre uma miríade de organizações de inteligência e os sujeitos políticos interessados no Congresso Nacional, no Poder Executivo e na própria sociedade. Em resumo, na Figura 4 encontra-se

Figura 4

Os Três Sistemas de Inteligência no Brasil

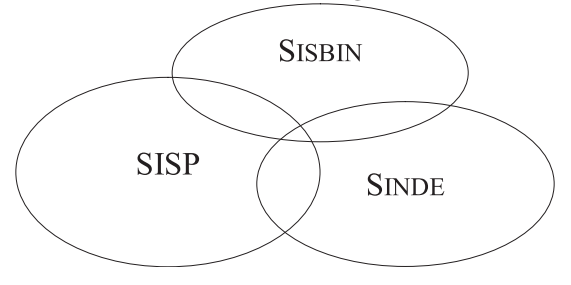


uma representação da relação entre os três sistemas que considero mais aproximada da dinâmica de poder de facto e da distribuição setorial de recursos, mesmo que a lei diga que as áreas de inteligência militar e policial são subordinadas ao GSI e à ABIN por meio das regras de funcionamento do SISBIN.

\section{Prioridades, Políticas e Ênfases dos Dois Últimos Governos}

De acordo com a lei de criação do SISBIN, as prioridades para a obtenção e análise de informações são estabelecidas para todo o sistema por meio de uma Política Nacional de Inteligência e de diretrizes anuais. Ambos os instrumentos são de responsabilidade do Poder Executivo, ouvida a Comissão Mista do Congresso. A atual PNI foi enviada ao Congresso em maio de 2000 (Mensagem Presidencial no 135), tendo sido aprovada pela CCAI com algumas emendas em novembro de 2001. Porém, refletindo a fase inicial de estruturação do SISBIN e a necessidade de legitimar as novas estruturas de inteligência, a PNI tratou de procedimentos, limites e responsabilidades, com um nível muito baixo de explicitação de prioridades e ênfases temáticas.

Um indicador mais preciso sobre as diretrizes para o setor pode ser encontrado nas declarações públicas dos seus dirigentes durante o segundo mandato do presidente Fernando Henrique Cardoso (1999-2002). Por exemplo, na sua palestra de abertura do seminário realizado no Congresso Nacional em novembro de 2002, o general Alberto Cardoso (então ministro-chefe do GSI) destacou as áreas em que os órgãos de inteligência teriam produzido conhecimentos com impacto significativo nas decisões governamentais. Vale reproduzir a lista de temas mencionados: o acompanhamento de movimentos separatistas, o acompanhamento do atendimento das reivindicações dos movimentos sociais, as questões fundiárias, a proteção da população indígena, meio ambiente e biodiversidade, oportunidades e óbices para o desenvolvimento nacional (particularmente nas áreas de tecnologia de ponta e de aproveitamento de recursos naturais), grilagem de terras (especialmente na região amazônica), proliferação de armas de destruição em massa (em apoio às delegações brasileiras e agências multilaterais), segurança pública nos estados federados (em cooperação com o SISP), combate ao crime transnacional organi- 
zado, narcotráfico, tráfico de armas e "lavagem" de dinheiro, prevenção do terrorismo, movimentação de integrantes de organizações terroristas internacionais, acompanhamento e avaliação de conflitos externos (e potenciais reflexos para o país), acompanhamento das ações resultantes da aplicação do Plano Colômbia e dos seus possíveis desdobramentos para o Brasil. Além desta lista de temas, também foi mencionado o trabalho de implementação do chamado Programa Nacional de Proteção ao Conhecimento - PNPC e o trabalho realizado pelo Centro de Pesquisa para a Segurança das Comunicações CEPESC/ABIN, relacionados com os esforços do governo brasileiro nas áreas de segurança informacional, criptografia e contra-inteligência ${ }^{33}$.

Embora não esteja ainda disponível para o público uma sistematização semelhante do leque temático do trabalho de inteligência do governo Lula (2003-2006), o Conselho de Governo definiu quatro grandes áreas temáticas como prioridades para 2003-2004: segurança pública e crime organizado (inclusive terrorismo e imigração ilegal); segurança da informação (inclui proteção ao conhecimento sensível); ameaças aos interesses nacionais e oportunidades, sobretudo na América do Sul; ameaças internas e externas ao Estado e à ordem democrática. As quatro áreas prioritárias foram subdivididas em dezoito temas específicos.

Em julho de 2004, em discurso proferido durante a posse do novo diretor-geral da ABIN, Mauro Marcelo de Lima e Silva, o próprio presidente Lula destacou a necessidade de a agência superar definitivamente a herança do passado por meio do fortalecimento da capacidade analítica coletiva e da relevância dos seus produtos, algo diretamente dependente do crescente profissionalismo dos seus funcionários. Sem dúvida, estes são alguns dos desafios da área de inteligência no Brasil após a implementação das mudanças estruturais em curso. Mas um problema adicional é o da alocação de recursos escassos para o cumprimento de uma missão definida de maneira genérica e volúvel segundo a crise política do momento. Isto fica evidente no grande leque temático e na ênfase (raramente questionada) em segurança interna. Estes três tópicos (recursos, profissionalização e qualidade dos produtos) necessitam de um comentário adicional (Mignone, 2004). 


\section{Dificuldades Persistentes: Recursos, Profissionalização e Qualidade dos Produtos}

O contexto mais geral das dificuldades de institucionalização das novas estruturas de inteligência no Brasil é dado pela falta de disposição das elites políticas no Poder Executivo e no Congresso Nacional em lidar com o problema da efetividade e eficiência dos serviços e unidades especializados no cumprimento de missões e mandatos legais definidos muito genericamente (o que remete às questões essenciais de prioridades, divisão de trabalho entre as agências, especialização, recursos, liderança etc.).

Junte-se a isso a resistência cada vez mais forte do Poder Judiciário a qualquer reforma que afete seus interesses corporativos, mesmo que isto possa contribuir para melhorar o desempenho estatal no provimento de segurança e bem-estar, além da baixa capacidade de pressão da sociedade civil nas áreas relacionadas à segurança do Estado, inteligência e defesa. Isto tudo foi traduzido na generalidade da linguagem utilizada nas leis e demais regulamentos que criaram os três subsistemas de inteligência, bem como na dispersão de temas e prioridades expressos pelos dois últimos governos.

Uma maneira mais direta de avaliar essas dificuldades é a observação do volume de recursos alocados para a atividade, o alcance do processo de profissionalização e a qualidade dos produtos de acordo com os usuários. Como salienta Dunnigan (2003:633), apesar de ser incerta a relação entre indicadores de input e capacidade combatente agregada, de modo geral a maioria dos governos acaba recebendo o nível de serviço que eles são capazes de pagar para receber.

Estimar os gastos governamentais com inteligência no Brasil é difícil, mas não tanto por causa dos limites impostos pelo segredo governamental. Em 2003, as despesas de caráter secreto ou reservado de várias naturezas (inclusive segurança e inteligência) somaram cerca de US\$ 3,5 milhões $(0,12 \%)$ para um gasto total de US\$ 291 bilhões. Entretanto, seja por decisão consciente ou por dificuldades inerentes à lógica do processo orçamentário brasileiro, mesmo os gastos que não são classificados como reservados são de difícil agregação a partir do orçamento geral da União - OGU ${ }^{34}$.

O fato é que não existem levantamentos sistemáticos sobre o gasto federal com o SISBIN, o SINDE e o SISP. Além de faltar uma base conceitu- 
al adequada e comparável internacionalmente, qualquer estimativa sobre a capacidade estatal brasileira na área de inteligência que fosse baseada apenas no volume total de recursos alocados pelo governo federal seria imprecisa, uma vez que se faz necessário levar em conta pelo menos as capacidades estaduais dos órgãos que compõem o SISP nos 26 estados e no Distrito Federal ${ }^{35}$.

Provisoriamente, pode-se tentar estimar o gasto brasileiro com inteligência a partir da soma do orçamento da ABIN (critério de unidade executora) com os valores que aparecem na subfunção "informações e inteligência" em todas as unidades executoras do Ministério da Defesa e do Ministério da Justiça.

No caso da ABIN, o orçamento para 2003 foi de cerca de US\$ 40 milhões, sendo que $73 \%$ deste total estava comprometido com despesas de pessoal (ativos e pensionistas), 21\% com o custeio e investimentos na atividade-fim da agência (cerca de US\$ 8,5 milhões) e 6\% com outros tipos de despesas. No caso do Ministério da Defesa, o valor autorizado, em 2004, para a subfunção 183 ("informações e inteligência") foi de aproximadamente US\$1 milhão (US\$ 700 mil para o DIE / MD e para o EMD; US\$230 mil para o Exército; US\$50 mil para a Marinha; e US\$ 30 mil para a Aeronáutica).

Apenas como exercício analítico, caso fossem mantidas as mesmas proporções encontradas na ABIN para a relação entre atividade-fim e gastos com pessoal (respectivamente, $21 \%$ e $73 \%$ de um total hipotético), a alocação de recursos para atividades relacionadas com inteligência (e "informações") na área de defesa seria algo em torno de US\$ 5,1 milhões em 2004. Procedimento semelhante foi adotado para o Ministério da Justiça, embora neste caso não seja possível fazer nenhuma extrapolação para o SISP, uma vez que a segurança pública é responsabilidade dos estados no sistema federativo brasileiro e, mesmo com as transferências federais de receitas, partes importantes do SISP ainda seriam custeadas pelos próprios estados. No caso do Ministério da Justiça, a subfunção "informações e inteligência" recebeu autorização de gastos da ordem de US\$3,9 milhões para 2004, elevando os gastos com inteligência nesse Ministério, seguindo-se a mesma lógica da estimativa feita para o Ministério da Defesa, para a faixa dos US $\$ 18,5$ milhões quando são acrescentadas as estimativas de gasto com pessoal ${ }^{36}$. 
A soma do orçamento geral da ABIN, mais as estimativas a respeito do SINDE e do Ministério da Justiça chega a US\$63,6 milhões para 2004. É difícil até mesmo estabelecer uma margem de erro percentual para este valor. Como estimativa do gasto brasileiro com inteligência, o exercício é precário por três razões: 1ํ) por um lado, o valor é muito alto, considerando-se a quantidade de coisas não relacionadas com a atividade de inteligência que, provavelmente, está incluída no item "inteligência e informações" dos orçamentos do Ministério da Defesa e do Ministério da Justiça; 2ª) por outro lado, é muito baixo, pois não leva em consideração os gastos dos governos estaduais com inteligência; 3ํ) além dessas limitações óbvias, há que se notar ainda que não foi incluído no exercício o complexo Sistema de Vigilância e Proteção da Amazônia (SIVAM/SIPAM), no qual já foram investidos mais de US $\$ 1,5$ bilhão e cuja capacidade operacional plena está prevista para 2004. Apesar dos caveats metodológicos destacados aqui, o Quadro 2 mostra claramente como os gastos brasileiros com inteligência são baixos em relação aos gastos totais com defesa.

\section{Quadro 2}

Recursos Parciais da Área de Inteligência no Brasil em 2003

\begin{tabular}{|c|c|c|c|c|}
\cline { 2 - 5 } \multicolumn{1}{c|}{} & $\begin{array}{c}\text { PIB } \\
\text { nominal }\end{array}$ & $\begin{array}{c}\text { Gasto } \\
\text { federal }\end{array}$ & Defesa & $\begin{array}{c}\text { Inteligência } \\
\text { estimativa } \\
\text { parcial } \\
\text { ABIN/SINDE/MJ }\end{array}$ \\
\hline $\begin{array}{c}\text { Valor em } \\
\text { dólares } \\
\text { correntes }\end{array}$ & 493 bilhões & 291 bilhões & 11 bilhões & 63,6 milhões \\
\hline $\begin{array}{c}\text { Percentual em } \\
\text { relação ao valor } \\
\text { da coluna } \\
\text { anterior }\end{array}$ & $\begin{array}{c}-0,2 \% \\
\text { (variação em } \\
\text { relação ao ano } \\
\text { anterior) }\end{array}$ & $58,9 \%$ & $3,8 \%$ & $0,57 \%$ \\
\hline
\end{tabular}

Ademais de um volume de recursos aparentemente muito baixo, o alto grau de comprometimento dos orçamentos de defesa, segurança pública e inteligência com despesas de pessoal e dívidas torna ainda mais difícil o desafio da profissionalização.

A lei que definiu, finalmente, um Plano Especial de Cargos para a ABIN (Lei no 10.862/2004) foi um passo além na direção de uma maior profissionalização do sistema de inteligência brasileiro. Ao criar uma 
carreira de analista de informações de nível superior, com requisitos de ingresso, treinamento, progressão e aposentadoria, a nova legislação confere um sentido de longo prazo para o planejamento de recursos e capacidades. Além disso, mesmo que sua estrutura de incentivos e sanções ainda demande significativos aperfeiçoamentos para evitar distorções corporativas, de modo geral ela aponta para a consolidação de critérios meritocráticos e publicamente defensáveis para a profissão. Isto parece decisivo considerando que a ABIN vem recebendo um número crescente de candidatos para o concurso de provas e títulos (9.064 candidatos para 120 vagas em 1999 e 10.546 candidatos para 61 vagas no concurso de 2000). Por outro lado, a ABIN também vem tendo grande dificuldade de manter esses jovens analistas. Afinal, dos 300 concursados desde 1995 restavam apenas 128 na Agência em agosto de 2004. Em termos de capacidade de treinamento, a partir de 2002 a Escola de Inteligência passou a atender uma demanda crescente de cursos por parte de órgãos integrantes do SISBIN, sendo que naquele ano foram realizados dezenove cursos com 414 participantes, número que subiu para 1.418 alunos em $2003^{37}$.

Considerando uma demanda crescente por treinamento nas áreas cada vez mais complexas de operações e análise, em contraste com uma oferta educacional por parte das escolas de inteligência do governo federal cada vez mais ameaçada pela falta de recursos e de pesquisas, parece claro que um dos aspectos centrais a observar no desenvolvimento da área de inteligência no Brasil é justamente o vínculo entre profissionalização e qualidade dos produtos de inteligência. Ademais, a profissionalização das atividades de inteligência no Brasil ainda depende de um longo percurso no que diz respeito às Forças Armadas e à polícia ${ }^{38}$.

\section{CONCLUSÃO}

Para resumir então uma longa caminhada, vejamos algumas conclusões preliminares do exercício. Em primeiro lugar, o regime político brasileiro é uma democracia consolidada, com importantes déficits estruturais e atitudinais que são refletidos em medidas mais desagregadas de liberdade e igualdade. Em termos de capacidade estatal, embora no contexto latino-americano o Brasil seja um país com um Estado forte, tanto do ponto de vista da exação de tributos quanto da defesa nacional, em comparação com os dez países mais industriali- 
zados e poderosos do mundo o Estado brasileiro está fragilizado pela vulnerabilidade da economia a choques externos, pelo alto grau de endividamento público e pela baixa capacidade de investimento e custeio na área de defesa. Estes e outros fatores limitam o desempenho governamental no provimento de segurança e bem-estar ${ }^{39}$.

Nesse contexto, as reformas estruturais brasileiras na área de inteligência foram em larga medida bem-sucedidas do ponto de vista de sua adequação ao contexto de um regime democrático consolidado. Mais do que isso, como destaca Bruneau (2003), elas são uma parte importante da própria consolidação democrática. Denúncias e escândalos de violações de regras democráticas apareceram ao longo desse processo e estão no centro das preocupações do novo governo de centro-esquerda em relação ao papel a ser desempenhado pelos sistemas de inteligência nas áreas de política externa, defesa nacional e segurança pública. De modo geral, os problemas verificados na área de inteligência também são consistentes com temas mais gerais de "institucionalização informal" (O'Donnell, 2001) e com as limitações estruturais do Estado e do regime político no Brasil. Entretanto, uma rápida pesquisa nos bancos de dados disponíveis com matérias da mídia mostra que nos dois últimos anos o tema da eficiência dos serviços tornou-se mais presente, ao lado das persistentes questões de legitimidade. Os Quadros 3 e 4 refletem este primeiro juízo a respeito do caso brasileiro, respectivamente, do ponto de vista da legitimidade e da efetividade ${ }^{40}$.

Quadro 3

Legitimidade dos Serviços de Inteligência Brasileiros (2004) ${ }^{41}$

\begin{tabular}{|c|c|c|c|c|}
\cline { 3 - 5 } \multicolumn{2}{|c|}{} & \multicolumn{2}{c|}{ Grau de Pervasividade do Serviço na Sociedade ${ }^{42}$} \\
\cline { 2 - 5 } & alto & $\begin{array}{c}\text { alto } \\
\text { PM-2 (27) Polícias } \\
\text { Civis (27) }\end{array}$ & mPF/MJ & baixo \\
\hline $\begin{array}{c}\text { Grau de } \\
\text { autonomia do } \\
\text { serviço/unidade } \\
\text { de inteligência em } \\
\text { relação ao governo } \\
\text { central }\end{array}$ & médio & CIE/CIM/CIAer & $\begin{array}{c}\mathrm{ABIN} \\
\mathrm{EMD}-2\end{array}$ & DIE/MD \\
\cline { 2 - 5 } & baixo & $\mathrm{MF}$ & $\begin{array}{c}\mathrm{MS} / \mathrm{MT} / \mathrm{MIR} \\
/ \mathrm{MCT} / \mathrm{MPS}\end{array}$ & SENASP/MJ/MRE \\
\hline
\end{tabular}


Quadro 4

Efetividade dos Serviços de Inteligência Brasileiros (2004)

\begin{tabular}{|c|c|c|c|c|}
\hline & & \multicolumn{3}{|c|}{ Grau de Profissionalização } \\
\hline & & alto & médio & baixo \\
\hline \multirow{3}{*}{$\begin{array}{c}\text { Recursos } \\
\text { dedicados para a } \\
\text { atividade-fim }\end{array}$} & alto & $\begin{array}{c}\text { CIE/CIM/CIAer } \\
\text { MF }\end{array}$ & DIE/MD & $\mathrm{DPF} / \mathrm{MJ}$ \\
\hline & médio & $\begin{array}{c}\text { ABIN } \\
\text { EMD-2 }\end{array}$ & PM-2 (27) & SENASP / MJ \\
\hline & baixo & MT/MPS & MS/MIT/MCT & $\begin{array}{c}\text { Polícias Civis (27) } \\
\text { MRE }\end{array}$ \\
\hline
\end{tabular}

Estes dois quadros refletem um juízo provisório e pessoal do autor com base na escassa evidência disponível, e não devem ser lidos como mais do que mera opinião relativamente "educada" a respeito da natureza da atividade e da trajetória recente do caso brasileiro. Do ponto de vista das escolhas fundamentais que os governantes das "novas democracias" teriam que fazer em relação à área de inteligência, pode-se dizer então que no caso do Brasil essas escolhas foram feitas, tratando-se a partir de agora de avaliar seu impacto segundo critérios comparativos internacionais, bem como em relação às ameaças e vulnerabilidades da segurança estatal e dos cidadãos no Brasil.

A primeira das três escolhas fundamentais diz respeito às capacidades ou funções "clássicas" da atividade que seriam priorizadas (coleta, análise, contra-inteligência e operações encobertas). No caso do Brasil, com a importante exceção da complexa arquitetura de coleta de inteligência de sinais e imagens associada ao Sistema de Vigilância da Amazônia, a prioridade declarada e observada tem sido posta nas funções de análise e contra-inteligência. As agências brasileiras de inteligência são proibidas por lei de realizar operações encobertas no exterior ou no território nacional, embora violações parciais a esta regra nos conduzam às demais escolhas cruciais que foram feitas ao longo do período 1995-2004.

O segundo conjunto de escolhas diz respeito ao balanço entre capacidades civis e militares. Neste aspecto, o caso brasileiro claramente destaca o componente civil do sistema, não apenas definindo a ABIN como órgão central do SISBIN, mas incorporando ao conselho do sistema os ministérios civis de maior peso, como a Casa Civil, Justiça e Relações Exteriores. A mesma estrutura se encontra reproduzida no 
caso do sistema de inteligência de defesa, coordenado pelo Departamento de Inteligência Estratégica do Ministério da Defesa. Embora no caso do SINDE o grau de autonomia das agências de inteligência das três forças possa ser considerado excessivo, ele é em parte neutralizado pela própria alocação de recursos, a qual é em grande medida decidida pelos componentes civis do SISBIN.

Note-se que não se está afirmando que esta divisão de recursos é necessariamente algo bom em si mesmo. No caso do Brasil, ela reflete em parte uma outra decisão altamente problemática, a de priorizar quase que exclusivamente os problemas de segurança domésticos ou internos, em detrimento da coleta e análise de inteligência sobre segurança internacional. Essa escolha decorre de demandas dos próprios usuários (ministros, Presidência da República, comandantes militares e dirigentes da área de segurança pública) e parece ter sido reforçada no novo governo de centro-esquerda, mas reflete também o arranjo institucional extremamente dependente de consensos e pretensamente cooperativo do SISBIN, em que cada burocracia tradicional (diplomacia, militares, policiais) na verdade tem reafirmado sua jurisdição e contido o processo de profissionalização da atividade.

As duas principais instâncias integradoras dos fluxos de inteligência (o próprio GSI e os conselhos dos três sistemas) são também as principais arenas institucionais mediadoras da relação entre os usuários (policymakers) e os serviços de inteligência. Sobre essas instâncias e sobre a Comissão Mista de Controle das Atividades de Inteligência do Congresso Nacional recairá o foco da avaliação sobre a efetividade e a legitimidade das novas estruturas de inteligência adotadas pelo governo brasileiro ao longo dos próximos anos.

(Recebido para publicação em outubro de 2004) (Versão definitiva em fevereiro de 2005) 


\section{NOTAS}

1. Ao longo do artigo, por democracia entenda-se o que Dahl (1997) chama de poliarquia.

2. Outros trabalhos recentes sobre os serviços de inteligência no Brasil são Antunes e Cepik (2003), Cepik e Antunes (2003) e Bruneau (2003). Para contextualizações históricas e comparativas, ver Antunes (2002) e Stepan (1988). Para um marco analítico mais desenvolvido sobre a relação entre inteligência e democracia, ver Cepik (2003).

3. Esta premissa corresponde ao alerta de Linz e Stepan (1996) para o fato de que "sem Estado não há democracia possível" em um mundo de Estados. Para um aprofundamento inicial sobre as atividades de inteligência como dimensões do poder de Estado na paz e na guerra, ver Herman (1996; 2001).

4. O relatório da comissão nacional de investigação sobre o desempenho dos serviços de inteligência dos Estados Unidos diante dos ataques terroristas de 11 de setembro de 2001 demonstra a atualidade do problema para todos os países (cf. Kean e Hamilton, 2004, esp. caps. 11, 12 e 13).

5. Para um comentário útil sobre diferentes comunidades epistêmicas nas áreas de Estudos de Inteligência e Relações Internacionais, ver Fry e Hochstein (1993).

6. A crítica da idéia anti-republicana de que existiria um trade-off claro entre efetividade e legitimidade das instituições políticas é feita em Cepik (2003).

7. O quarto critério corresponde à chamada oitava condição de Dahl (1997) para a vigência da poliarquia.

8. Por definição, a subdisciplina de "transitologia" analisaria então períodos temporais de até vinte anos (do fim de um regime político à consolidação de outro). Outros fatores importantes para a avaliação da "durabilidade" de regimes políticos consolidados seriam o nível de desenvolvimento socioeconômico, a capacidade estatal, o efeito das instituições políticas vigentes, a maior ou menor desigualdade social, a legitimidade das instituições políticas e sociais, sua maior ou menor informalidade e o contexto internacional (cf. Lane e Ersson, 1994; Linz e Stepan, 1996; Przeworski et alii, 2000; Diamond e Plattner, 2001; e Schedler, 2001b).

9. Para o caso dos Estados Unidos, dois estudos neo-institucionalistas relevantes sobre segurança nacional e democracia são Zegart (1999) e Feaver (2004).

10. No último country report disponível no âmbito do projeto Polity IV (2004), o Brasil foi classificado como altamente democrático ( 8 pontos em uma escala de 0 a 10), e a última transição para a democracia foi localizada no ano de 1985 (cf. $<$ www.cidcm.umd.edu>).

11. Como se sabe, a Freedom House utiliza uma classificação final triádica (livre, parcialmente livre, não-livre) baseada em uma escala de 1 (mais livre) a 7 (menos livre) para dois conceitos agregados: direitos políticos (PR) e liberdades civis (CL). Na tabela de 2004 (que avalia os acontecimentos do ano de 2003), o Brasil recebeu notas 2 (PR) e 3 (CL). A Venezuela recebeu 3 (PR) e 4 (CL), enquanto a Colômbia recebeu 4 (PR) e 4 (CL). Em 2004, de maneira não surpreendente em função do viés pró-liberal da fundação, a Freedom House considerava, respectivamente, o Chile como o país 
mais livre (1) e Cuba como o país menos livre (7) da América Latina (cf. Freedom House, 2004).

12. Para um exemplo de como são feitas essas avaliações internacionais de risco político, ver Political Risk Services (2004).

13. Note-se que se trata de observar os gastos e prioridades substantivas no processo de produção de políticas públicas, e não de aceitar como válido o "teste de alternância" proposto por alguns institucionalistas de inclinação pró-majoritária. Considerar a alternância de poder entre partidos como um indicador de consolidação ou de qualidade democrática, simplesmente reforça um viés a favor de sistemas majoritários de votação e polarização bipartidária, duas características institucionais que estão longe de representar a única ou a mais eficaz e eficiente forma de arranjo democrático (cf. Lijphart, 2003).

14. Trata-se aqui de juízo baseado na observação externa dos comportamentos dos sujeitos coletivos relevantes (elites civis, grupos sociais diversos, governos estrangeiros, Forças Armadas etc.) e da verificação empírica sobre a ocorrência ou não de um único tipo de evento (interrupção violenta dos procedimentos democráticos definidos acima) com várias nuances e formas específicas. Quanto mais exigentes os critérios, menor o número de países e/ou de períodos históricos que poderão ser considerados democráticos ou, no caso da definição adotada aqui, democracias consolidadas. Para discussões adicionais sobre estes pontos, ver Diamond e Plattner (2001) e, também, Collier e Levitsky (1997). Para os problemas de operacionalização conceitual, periodização e mensuração da consolidação em diferentes países e períodos, ver Schedler (2001a; 2001b).

15. Cabe mencionar, de passagem, que faz muita falta dentro da própria literatura sobre teoria democrática e instituições comparadas um esforço de modelagem analítica que combine critérios verticais (níveis de democratização) e horizontais (modelos de democracia). Sobre a construção de capacidade estatal na América Latina, ver Geddes (1994). Para a centralidade do particularismo como instituição informal das "novas democracias" e de outros países considerados poliárquicos (e.g. Índia, Itália e Japão), ver O’Donnell (2001).

16. Tenho opinião contrária à de Bolivar Lamounier em seu capítulo sobre o Brasil no livro de Dominguez e Shifter (2003:269-291), em particular sobre a origem histórica e institucional dos déficits democráticos e de capacidade governamental no país, mas importa destacar como o debate acadêmico brasileiro sobre a democracia se deslocou do programa de pesquisa da transição para o das conseqüências de diferentes arranjos institucionais. No caso, Lamounier critica o que ele considera um excessivo componente "consensual" na democracia brasileira, em oposição a uma melhor eficiência "majoritária" que deveria ser buscada. Embora ele não realize o trabalho de avaliação sistemática sugerido pela tentativa de integrar o Brasil na tipologia de Arend Lijphart (2003), vale como uma provocação sobre o tema (ver, ainda, Carrillo, 2001 e Polity IV, 2004).

17. A necessidade de um vínculo mais forte entre os estudos de inteligência (Intelligence Studies) e a área de relações civil-militares é destacada em Bruneau e Dombroski (no prelo).

18. Para um panorama dos estudos sobre as relações civil-militares na América Latina, ver D’ Araújo e Castro (2000), Pion-Berlin (2001), Trinkunas (2000), Stanley (2001), 


\section{Marco Cepik}

Fitch (1998) e Aguero (1998). Para uma discussão metodológica recente sobre critérios de classificação de regimes autoritários, ver Geddes (2003).

19. Note-se que ambos os padrões profissionais de atribuição de missões para as Forças Armadas ("clássico" e "desenvolvimentista") são, em princípio, compatíveis com regimes democráticos. No caso da América Latina, em anos recentes, esse padrão desenvolvimentista ocorre na Venezuela, onde $74 \%$ dos entrevistados pela pesquisa do Latinobarómetro declaram apoiar a democracia, e um padrão "clássico-huntingtoniano" prevalece no Uruguai, onde 78\% da população declara ser favorável à democracia. Por outro lado, controle civil sobre os militares ocorre tanto em contextos democráticos quanto autoritários. Exemplos contemporâneos de controle da liderança política sobre as Forças Armadas em contextos não democráticos são China e Cuba. Ainda assim, aceita-se em geral a falta de controle dos governantes sobre as Forças Armadas como um indicador de fragilidade institucional incompatível com a oitava condição de Dahl para a existência de uma poliarquia ("os representantes eleitos podem governar sem a tutela de grupos de poder não eleitos"). Nos chamados "novos autoritarismos competitivos" - países que faziam parte da ex-URSS -, uma das características que impedem chamá-los de democracias são as dificuldades de subordinação das Forças Armadas e/ou das forças de segurança e polícias políticas.

20. Contrastar, por exemplo, as abordagens de Hunter (1997) e Zaverucha (2000). Para uma avaliação da legislação brasileira relevante, ver $<w w w . s e n a d o . g o v . b r>$ (Prodasen). Para uma visão geral das estruturas de defesa, cf. $<$ www.resdal.org $>$. O episódio que levou à queda do então ministro da Defesa brasileiro, embaixador José Viegas, em novembro de 2004, mostrou que, de um lado, setores das Forças Armadas ainda recusam os procedimentos democráticos. Por outro lado, demonstrou como as autoridades civis no Brasil ainda não têm a menor idéia do papel a ser desempenhado pelas Forças Armadas na inserção internacional do país e na melhoria do desempenho do Estado brasileiro nas áreas de segurança e defesa. Para os requisitos e componentes de uma política de defesa cuja ausência impede uma melhoria do desempenho do regime político brasileiro em termos de legitimidade e efetividade do poder militar do Estado, cf. Proença Jr. e Diniz (1998).

21. Para uma discussão mais detalhada sobre as transformações ocorridas na estrutura do Estado brasileiro ao longo dos últimos quinze anos, ver Sallum Jr. (2003). Para um argumento institucionalista histórico acerca da relação entre democracia, guerra e construção do Estado na América Latina, ver López-Alves (2000).

22. Em 1999, em conseqüência dos sucessivos choques externos decorrentes da crise financeira na Ásia e na Rússia, o então governo Fernando Henrique Cardoso foi forçado (após um ataque especulativo que derrubou as reservas e provocou evasão de capitais) a abandonar o regime de bandas cambiais (crawling peg), passando a regular o valor da moeda por meio de instrumentos de mercado e com força institucional possibilitada pelo fato de os três bancos federais não terem sido privatizados e o Banco Central ter sido "realinhado" com a realidade macroeconômica do país. Após os ataques terroristas de 11 de setembro de 2001 nos Estados Unidos, a crise argentina de 2001-2002 e o uso político do pânico financeiro como arma eleitoral pelo governo Cardoso, o Brasil atravessou uma crise bastante séria, com contração de $0,2 \%$ do PIB real em 2003. 
23. Tais medidas e informações são meramente indicativas, uma vez que James Dunnigan não explicita suas fontes e fórmulas de cálculo para cotejamento crítico com outras fontes, tais como o Military Balance (IISS), o Jane's Group ou o Ministério da Defesa do Brasil. São apresentadas aqui apenas para dar uma escala de grandeza e um procedimento analítico na avaliação da capacidade estatal brasileira. Segundo Dunnigan (2003:632-633), o conceito de capacidade de combate terrestre (land combat power) abarca a capacidade de combate total das Forças Armadas de um país com exceção da Marinha de Guerra. Trata-se de um índice composto, formado por indicadores quantitativos e juízos qualitativos a respeito de equipamentos, armas e tropas. O índice de qualidade total (total force quality) é uma fração pela qual o valor bruto da capacidade de combate deveria ser multiplicado para dar conta de fatores "soft" de capacidade (liderança, suporte, instituições etc.). O número de efetivos leva em conta apenas a quantidade de pessoal uniformizado, independente de desempenharem funções de suporte ou de pertencerem a unidades de combate. O orçamento militar foi estimado pelo autor com uma margem de erro de $10 \%$. Segundo o Jane's Group, em 2002, o gasto brasileiro com defesa teria sido de US\$ 10,7 bilhões, representando então 2,4\% do PIB. O gasto anual por soldado é uma medida agregada, dividindo orçamento por número de pessoal uniformizado, em dólares correntes. O número de veículos blindados inclui veículos blindados de transporte de tropas (armoured personnel carriers), tanques leves, tanques principais (main battle tanks) e outros veículos de suporte. O número de aeronaves não inclui interceptadores. No caso das forças navais, o índice de capacidade de combate é um valor numérico, refletindo a capacidade total da frota (para Dunnigan, o valor de combate naval dos Estados Unidos é de 302, o da Rússia é de 45, China 16 e México e Argentina alcançam valores similares, igual a 02. Os demais indicadores são auto-evidentes.

24. Para maiores detalhes, ver Rosieri (2004) e, também, Pederiva (2002).

25. Sobre o Serviço Nacional de Informações -SNI entre 1964 e 1990 e sobre a década de 90, ver Stepan (1988), Antunes (2002) e Antunes e Cepik (2003).

26. O mesmo não pode ser dito a respeito da legislação que regulamenta o direito dos cidadãos às informações governamentais, que permanece escassa e falha (Cepik, 2000). Para obter o texto integral da legislação brasileira em vigor, ver $<$ www.interlegis.gov.br>.

27. Para uma discussão detalhada dos conteúdos das atas das onze reuniões da CCAI, ver Antunes (2004). Para uma visão abrangente do seminário promovido pela CCAI em conjunto com a ABIN e outros órgãos, ver Brasil (2003).

28. Para uma discussão crítica dos limites institucionais de vários mecanismos de controle sobre a atividade de inteligência, ver Cepik (2003, esp. 3ª parte do cap. 3).

29. Previsto inicialmente para reunir-se uma vez por trimestre, o Conselho realizou quatro reuniões até agosto de 2004, tendo criado um Grupo de Integração para tentar melhorar a cooperação interagências.

30. De fato, o Decreto Executivo n-3.448, de 5 de maio de 2000, estabeleceu o SISP como parte do SISBIN e designou a própria ABIN como órgão central do SISP. Devido a problemas operacionais e disputas entre a ABIN e o Ministério da Justiça, um novo Decreto Executivo (n⿳ 3.695, de 21 dezembro de 2000) transferiu a coordenação do SISP para a Secretaria Nacional de Segurança Pública do Ministério da Justiça - 


\section{Marco Cepik}

SENASP / MJ. Nos estados, o núcleo de gestão do SISP seriam os gabinetes de Gestão Integrada do Sistema Único de Segurança Pública - SUSP sob o comando do ministro da Justiça e do diretor da SENASP, com a participação das Polícias Federal e Rodoviária Federal, das Polícias Militares e Civis, Ministérios Públicos, Receita Federal e ABIN.

31. A estrutura regimental do MD está definida no Decreto n-5.201/2004, que deve ser consultado para uma melhor compreensão da relação entre o órgão central do SINDE e as agências centrais das forças singulares, formalmente representadas em um conselho do sistema nos termos da Portaria MD 295/2002.

32. É questionável o grau de coesão mesmo dentro de cada subsistema. No caso do SISP, por exemplo, há fortes resistências por parte da Polícia Federal em relação ao papel coordenador da SENASP. Existem também dificuldades entre a ABIN e a Polícia Federal, entre as Polícias Militares e as Polícias Civis nos estados, entre as Polícias Civis e os Ministérios Públicos, entre as polícias estaduais e a Polícia Federal etc. No caso do SINDE, é pouco provável que não existam resistências burocráticas à integração horizontal entre os serviços de cada Força, bem como resistências ao papel coordenador do DIE e do próprio MD.

33. Para o texto completo da palestra do general Cardoso, ver Brasil (2003).

34. Todos os valores foram convertidos em dólares, considerando uma taxa de câmbio de $\mathrm{R} \$ 3,00$ por dólar. A consulta ao OGU pode ser feita por meio do Sistema Integrado de Administração Financeira -SIAFI do governo federal ou na página da Câmara dos Deputados na Internet: <www.camara.gov.br/internet/orcament/principal/default.asp >. No OGU, o nível de agregação mais amplo das informações são as unidades (órgãos de primeiro escalão como a Presidência da República ou o Ministério da Defesa e unidades de autorização de despesa dentro destes órgãos, tais como a ABIN na PR ou o Exército no MD) e as funções governamentais (defesa, saúde etc.). As várias atividades e prioridades governamentais são organizadas em Programas que são compostos de Ações. Cada Ação, vinculada ao seu Programa específico, é classificada - teoricamente de acordo com o objeto em si da Ação - em Funções (defesa nacional ou segurança pública, por exemplo) e Subfunções. A linha do orçamento referente à "Informação e Inteligência" é, portanto, uma Subfunção (n- 183). Sobre os problemas associados ao uso do orçamento para deduzir indicadores de desempenho, cf. Pederiva (2002).

35. Para uma idéia geral da importância das polícias estaduais, note-se que enquanto as Forças Armadas brasileiras somavam cerca de 295 mil efetivos em 2003 (195 mil no Exército), os efetivos policiais do governo federal e dos estados somavam mais de 500 mil em 2001 (dos quais cerca de 15 mil na Polícia Federal, 376 mil nas Polícias Militares estaduais encarregadas de patrulhamento e prevenção e 103 mil nas Polícias Civis estaduais encarregadas de investigação e repressão ao crime). Também precisariam ser levados em conta recursos indiretos e assistência internacional (especialmente dos Estados Unidos no caso das operações antinarcóticos), tema que foi objeto de debate polêmico na mídia brasileira no começo de 2004 e pauta de reuniões das comissões congressuais de controle externo (CCAI e CSPCCO).

36. Esta utilização da subfunção "informação e inteligência" também é problemática para estimar gastos com inteligência de maneira realista. Considerando todos os órgãos com Ações classificadas nesta subfunção no OGU de 2004 do governo fede- 
ral, a subfunção 183 acaba incluindo ações tão distantes da área de inteligência como a construção da Rede de Bibliotecas Virtuais em Saúde (Ação 6189) ou o desenvolvimento de um Cadastro Nacional de Profissionais e Estabelecimentos Assistenciais de Saúde (Ação 6153). Tal constatação advém de pesquisa específica realizada com dados coletados em banco de dados (Access) da Câmara dos Deputados, considerando a execução orçamentária acumulada até 24/7/2004. Cf. $<$ www.camara.gov.br/internet/orcament/principal/default.asp $>$.

37. Para uma discussão mais detalhada sobre os quatro critérios utilizados para avaliar a profissionalização da atividade de inteligência no Brasil (conhecimentos específicos, carreira, formação e código de ética), embora anterior à promulgação da Lei no 10.862/2004, ver Cepik e Antunes (2003).

38. Uma possível solução seria aumentar a cooperação entre a EsINT (Escola de Inteligência da ABIN), a Escola de Inteligência do Exército, a Escola Superior de Guerra e outras escolas superiores no âmbito federal com currículos complementares (e.g. Escola Superior de Administração Pública, Escola Superior do Ministério Público da União, Colégio Nacional de Procuradores-Gerais de Justiça etc.), o que poderia ser feito por meio de convênios com universidades e esforços internos de coordenação no âmbito do SISBIN, SINDE e SISP. Porém, mesmo que tal sinergia pudesse ser obtida existe uma precondição para que os resultados gerados tenham impacto sobre a efetividade e a legitimidade dos sistemas: essas instituições precisam ser submetidas aos mesmos processos avaliativos externos que outras instituições educacionais brasileiras de nível superior, tais como o sistema de avaliação da pós-graduação conduzido pela CAPES/MEC e os critérios utilizados pelo $\mathrm{CNPq} / \mathrm{MCT}$ para apoio à pesquisa.

39. Outros fatores a mencionar seriam o peso da economia informal, o número insuficiente de funcionários de carreira em burocracias estatais especializadas (fiscal, militar, financeira, inteligência, diplomática etc.), o desperdício causado por ausência de planejamento e a corrupção. Cabe destacar que o setor público na América Latina tem, em média, metade do tamanho do setor público nos países mais industrializados e ricos (Franko, 2003:162).

40. Por exemplo, as duas trocas de diretores-gerais da ABIN ocorridas desde a criação da agência foram decorrentes de problemas associados à legitimidade e não à eficiência. Em 2001, o primeiro diretor-geral da agência, coronel (Reserva) Ariel de Cunto, foi afastado do cargo após a divulgação na imprensa de que havia nomeado para a direção do Setor de Acompanhamento de Organizações Criminosas da ABIN o tenente Del Menezzi, o décimo nome na lista dos torturadores mais denunciados pelo grupo Brasil: Nunca Mais - BNM. O cel. De Cunto assumiu que tinha conhecimento dessas acusações, mas insistiu na manutenção do tenente no cargo. Foi apenas depois destas denúncias que a ABIN se prontificou a fazer um cruzamento entre os nomes de seus servidores com os 444 nomes de torturadores denunciados pelo BNM. Em julho de 2004, a segunda diretora-geral da ABIN, Marisa Del'Isola Diniz (a primeira mulher a dirigir um serviço de inteligência na América do Sul), deixou o cargo em meio a uma série de desgastes associados a disputas entre grupos dentro da ABIN que chegaram à Justiça e às ruas na forma de manifestações sindicais, mas também em decorrência de denúncias de envolvimento de funcionários da ABIN em atos de espionagem contra membros do governo Lula. No discurso de pos- 


\section{Marco Cepik}

se do terceiro diretor-geral da ABIN em menos de cinco anos, o presidente Lula enfatizou a agenda da profissionalização e da agilidade (efetividade, eficácia e eficiência) como condições de legitimação da atividade de inteligência no Brasil.

41. Tabela adaptada da tipologia de serviços de inteligência de segurança desenvolvida por Gill (1994:82).

42. O termo "pervasividade" é derivado do inglês pervasiveness, e me parece preferível a outras alternativas como "intromissão" ou "penetração". 


\section{REFERÊNCIAS BIBLIOGRÁFICAS}

AGUERO, Felipe. (1998), "Legacies of Transitions: Institutionalization, the Military and Democracy in South America". Mershon International Studies Review, no 42, pp. 383-404.

ANTUNES, Priscila. (2002), SNI \& ABIN: Entre a Teoria e a Prática. Uma Leitura dos Serviços Secretos Brasileiros ao longo do Século XX. Rio de Janeiro, Fundação Getulio Vargas Editora.

. (2004), Controle da Atividade de Inteligência no Brasil: Legitimidade e Eficiência enquanto Desafio Institucional. Trabalho apresentado no XXV Latin America Studies Association Congress. Riviera Hotel/Las Vegas, 7-10 de outubro, http://lasa.international.pitt.edu.

_ e CEPIK, Marco A. C. (2003), “The New Brazilian Intelligence System: An Institutional Assessment". International Journal of Intelligence and Counterintelligence, vol. 16 , n을. pp. 349-373.

BARRY, Brian. (1991), “Is Democracy Special?" , in Democracy and Power: Essays in Political Theory. Oxford/UK, Clarendon Press, 2 vols.

BRASIL. (2003), Anais do Seminário Atividades de Inteligência no Brasil: Contribuições para a Soberania e a Democracia. Brasília, ABIN/Congresso Nacional, pp. 179-198.

BRUNEAU, Thomas. (2003), Prospects for Intelligence and Security Services Reforms in Brazil. CCMR/NPS, Monterey, CA. Manuscrito.

e DOMBROSKI, Kenneth. (no prelo), "Reforming Intelligence: The Challenge of Control in New Democracies", in T. Bruneau eS. Tollefson (eds.), Soldiers and Statesmen: Institutional Bases of Democratic Civilian Control. Austin, TX, University of Texas Press.

CARRILlO, Fernando F. (ed.). (2001), Democracia en Déficit: Gobernalidad y Desarrollo en América Latina y el Caribe. Washington, D.C., BID.

CEPIK, Marco A. C. (2000), “Direito à Informação: Situação Legal e Desafios”. Informática Pública, no 4, pp. 43-56.

. (2003), Espionageme Democracia. Rio de Janeiro, Fundação Getulio Vargas Editora.

e ANTUNES, Priscila. (2003), “The Professionalization of Intelligence in Brazil: Knowledge, Career Path, and Values", in R. Swenson eS. Lemozy (eds.), Intelligence as a Profession in the Americas: New Approaches. Washington, D.C., JMIC Edition, pp. 109-154.

COLLIER, David e LEVITSKY, Steven. (1997), “Democracy with Adjectives: Conceptual Innovation in Comparative Research". World Politics, no 49, pp. 430-451.

D'ARAÚJO, Maria Celina e CASTRO, Celso. (2000), Democracia e Forças Armadas no Cone Sul. Rio de Janeiro, Fundação Getulio Vargas Editora.

DAHL, Robert. (1997) [1971], Poliarquia: Participação e Oposição. São Paulo, Edusp.

DIAMOND, Larry e PLATTNER, Mark (eds.). (2001), The Global Divergence of Democracies. Baltimore, The Johns Hopkins University Press. 


\section{Marco Cepik}

DOMINGUEZ, Jorge e SHIFTER, Michael (eds.). (2003), Constructing Democratic Governance in Latin America (2 2 ed.). Baltimore, The Johns Hopkins University Press.

DUNNIGAN, James. (2003), How to Make War: A Comprehensive Guide to Modern Warfare in the 21st Century (4 $4^{\mathrm{a}}$ ed.). New York, Quill.

FEAVER, Peter. (2004), Armed Servants: Agency, Oversight, and Civil-Military Relations. Cambridge, MA, Harvard University Press.

FITCH, Samuel. (1998), The Armed Forces and Democracy in Latin America. Baltimore, The Johns Hopkins University Press.

FRANKO, Patrice M. (2003), The Puzzle of Latin American Economic Development (2 2 ed.). Boston, Rowman \& Littlefield.

FREEDOM HOUSE. (2004), Freedom in the World 2004: Table of Independent Countries Comparative Measures of Freedom. Disponível em <www.freedomhouse.org $>$. Acessado em 10 de agosto de 2004.

FRY, Michael G. e HOCHSTEIN, Miles. (1993), “Epistemic Communities: Intelligence Studies and International Relations". Intelligence and National Security, vol. 8, n을, pp. 14-28 ( $\mathrm{n}$ - especial sobre Espionage: Past, Present, Future? Editado por Wesley K. Wark).

GEDDES, Barbara. (1994), Politician's Dilemma: Building State Capacity in Latin America. Berkeley, CA, University of California Press.

. (2003), Paradigms and Sand Castles: Theory Building and Research Design in Comparative Politics. Ann Harbor, MI, The University of Michigan Press.

GILL, Peter. (1994), Policing Politics: Security Intelligence and the Liberal Democratic State. London, FrankCass.

HERMAN, Michael. (1996), Intelligence Power in Peace and War. Cambridge/UK, Cambridge University Press.

(2001), Intelligence Services in the Information Age. London, FrankCass.

HUNTER, Wendy. (1997), Eroding Military Influence in Brazil: Politicians against Soldiers. North Carolina, The University of North Carolina Press.

HUNTINGTON, Samuel P. (1975) [1968], A Ordem Política nas Sociedades em Mudança. São Paulo, Forense/Edusp.

KEAN, Thomas e HAMILTON, Lee. (2004), The 9/11 Commission Report: Final Report of the National Commission on Terrorist Attacks upon the United States. New York, Norton \& Company (edição autorizada).

KINGSTONE, Peter e POWER, Timothy (eds.). (2000), Democratic Brazil: Actors, Institutions, and Processes. Pittsburgh, PA, University of Pittsburgh Press.

LANE, Jan-Erik e ERSSON, Svante. (1994), Comparative Politics: An Introduction and New Approach. Cambridge, MA, Polity Press.

LATINOBARÓMETRO. (2004), Informe - Resumen: Una Década de Mediciones. Santiago de Chile, Corporación Latinobarómetro. Disponível em <www.latinobarometro.org $>$. Acessado em 14 de agosto de 2004. 
LIJPHART, Arend. (2003) [1999], Modelos de Democracia: Desempenho e Padrões de Governo em 36 Países. São Paulo, Civilização Brasileira.

LINZ, Juan e STEPAN, Alfred. (1996), Problems of Democratic Transition and Consolidation: Southern Europe, South America, and Postcommunist Europe. Baltimore, The Johns Hopkins University Press.

LÓPEZ-ALVES, Fernando. (2000), State Formation and Democracy in Latin America: 1810-1900. Durham, NC, Duke University Press.

MAINWARING, Scott, BRINKS, Daniel e PÉREZ-LIÑÁN, Aníbal. (2001), “Classificando Regimes Políticos na América Latina (1945-1999)”. Dados, vol. 44, no 4, pp. 645-687.

MIGNONE, Ricardo. (2004), “Novo Diretor da ABIN Diz que Órgão Será Transparente”. Brasília, Folha Online. Disponível em <www.folhaonline.com.br $>$. Acessado em 13 de julho de 2004. Discurso completo do presidente disponível na Agência Brasil.

O'DONNELL, Guillermo. (2001), "Illusions about Consolidation”, in L. Diamond e M. Plattner (eds.), The Global Divergence of Democracies. Baltimore, The Johns Hopkins University Press, pp. 113-148.

PEDERIVA, João. (2002), A Defesa Brasileira e os Indicadores de Desempenho no Orçamento Federal do Brasil. Consultoria de Orçamento do Senado Federal, Brasília. Manuscrito.

PION-BERLIN, David (ed.). (2001), Civil-Military Relations in Latin America. North Carolina, The University of North Carolina Press.

POLITICAL RISK SERVICES. (2004), Brazil Country Forecast: 18 Month and Five Year Forecasts. Washington, D.C., PRS Group.

POLITY IV. (2004), Country Report: Brasil 2002. Baltimore, University of Maryland. Disponível em <www.cidcm.umd.edu>. Acessado em 15 de agosto de 2004.

PROENÇA JR., D. e DINIZ, E. (1998), Política de Defesa no Brasil: Uma Análise Crítica. Brasília, Ed. UnB.

PRZEWORSKI, Adam et alii. (2000), Democracy and Development: Political Institutions and Well Being in the World, 1950-1990. Cambridge/UK, Cambridge University Press.

ROJAS, Francisco A. (2004), "Seguridad en las Américas, los Desafíos Post-Conferencia: Operacionalizar los Consensos y Articular los Conceptos". FES Briefing Paper, maio, Bogota, Friedrich Ebert Stiftung, pp. 1-11.

ROSIERI, Antonio C. A. (2004), Alocação de Recursos na Função Defesa. Ciclo de Debates em Itaipava. Ministério da Defesa, Brasília. Disponível em <www.defesa.gov.br>. Acessado em 15 de agosto de 2004.

SALLUM JR., Brasilio. (2003), “Metamorfoses do Estado Brasileiro no Final do Século XX". Revista Brasileira de Ciências Sociais, vol. 18, no 52, pp. 35-55.

SCHEDLER, Andreas. (2001a), "Measuring Democratic Consolidation". Studies in Comparative International Development, vol. $36, \mathrm{n}-1$, pp. 66-92. 


\section{Marco Cepik}

. (2001b), “What Is Democratic Consolidation?", in L. Diamond e M. Plattner (eds.), The Global Divergence of Democracies. Baltimore, The Johns Hopkins University Press, pp. 149-164.

STANLEY, Ruth. (2001), "Modes of Transition vs. Electoral Dynamics: Democratic Control of the Military in Argentina and Chile". Journal of Third World Studies, vol. 18, no 2 , pp. 71-91.

STEPAN, Alfred. (1988), Rethinking Military Politics: Brazil and the Southern Cone. Princeton, NJ, Princeton University Press.

TILLY, Charles. (2003), The Politics of Collective Violence. Cambridge/UK, Cambridge University Press.

TRINKUNAS, Harold. (2000), “Crafting Civilian Control in Emerging Democracies: Argentina and Venezuela". Journal of Interamerican Studies and World Affairs, vol. 42, no 3, pp. 77-109.

ZAVERUCHA, Jorge. (2000), Frágil Democracia: Collor, Itamar, FHC e os Militares. Rio de Janeiro, Civilização Brasileira.

ZEGART, Amy. (1999), Flawed by Design: The Evolution of the CIA, JCS and NSC. Stanford, CA, Stanford University Press. 


\section{GLOSSÁRIO}

ABIN - Agência Brasileira de Inteligência

CCAI - Comissão Mista de Controle das Atividades de Inteligência (Congresso Nacional)

CCJSSP - Subcomissão Permanente de Segurança Pública (Comissão de Constituição, Justiça e Cidadania, Senado Federal)

CEPESC - Centro de Pesquisa para a Segurança das Comunicações

CIAer - Centro de Inteligência da Aeronáutica

CIE - Centro de Inteligência do Exército

CIM - Centro de Inteligência da Marinha

COAF - Conselho de Controle de Atividades Financeiras

COPEI - Coordenação Geral de Pesquisa e Investigação do Ministério da Fazenda

CRE - Comissão de Relações Exteriores e Defesa Nacional (Senado Federal)

CREDEN - Comissão de Relações Exteriores e Defesa Nacional (Câmara dos Deputados)

CSPCCO - Comissão de Segurança Pública e Combate ao Crime Organizado (Câmara dos Deputados)

DIE - Departamento de Inteligência Estratégica (parte da SPEAI/MD)

DPF - Departamento de Polícia Federal (parte do MJ)

DPRF - Departamento de Polícia Rodoviária Federal (parte do MJ)

EMD - Estado-Maior de Defesa

GSI - Gabinete de Segurança Institucional (parte da PR)

MCT - Ministério da Ciência e Tecnologia

MD - Ministério da Defesa

MF- Ministério da Fazenda

MIR - Ministério da Integração Regional

MJ - Ministério da Justiça

MPS - Ministério da Previdência Social

MRE - Ministério das Relações Exteriores (Itamaraty)

MS - Ministério da Saúde

MT - Ministério do Trabalho

OGU - Orçamento Geral da União

PM-2 - Segunda Seção (inteligência) da Polícia Militar (estados)

PNI - Política Nacional de Inteligência

PNISP - Plano Nacional de Inteligência de Segurança Pública

SENASP - Secretaria Nacional de Segurança Pública (parte do MJ) 
SIAFI - Sistema Integrado de Administração Financeira SINDE - Sistema de Inteligência de Defesa SIPAM - Sistema de Proteção da Amazônia SISBIN - Sistema Brasileiro de Inteligência SISP - Subsistema de Inteligência de Segurança Pública SIVAM - Sistema de Vigilância da Amazônia SNI - Serviço Nacional de Informações (1964-1990) SRF - Secretaria da Receita Federal SUSP - Sistema Único de Segurança Pública TCU - Tribunal de Contas da União 


\section{ABSTRACT \\ Political Regime and the Intelligence System in Brazil: Legitimacy and Effectiveness as Institutional Challenges}

This article aims to analyze the relationship between political regime and the organizational and legal structures of intelligence activities in Brazil. According to minimum aggregate measures, the country is approaching a threshold that allows one to consider it a consolidated democratic regime. This is expressed in a legal framework developed for the intelligence field, with explicit mechanisms for coordination, supervision, and oversight. However, there are persistent problems in the performance of new organizational structures that are also consistent with the challenges of democratic consolidation. The article demonstrates how the use of more disaggregated measurements of democratic consolidation and state capability allow a clearer association between the political regime's characteristics and the changes observed in different countries in the field of intelligence in the last fifteen years.

Key words: democracy; intelligence services; political regime; oversight

\section{RÉSUMÉ}

Régime Politique et Services de Renseignements au Brésil

Dans cet article, on cherche à analyser le rapport entre le régime politique et le profil organisationnel et légal des Services de Renseignements au Brésil. Grâce à un minimum de mesures qui se relient entre elles, ce pays se rapproche des seuils qui permettent de considérer le régime démocratique comme consolidé. Cela se traduit par un repère légal développé pour les Services de Renseignements, avec des mécanismes explicites de coordination, supervision et contrôle extérieur. Il reste pourtant des problèmes de performance des nouvelles structures organisationnelles qui sont en rapport avec les enjeux de la consolidation démocratique. On voit comment l'emploi de mesures isolées de consolidation démocratique et de capacité étatique permettent une association plus nette entre les caractéristiques du régime politique et les changements observés dans les Services de Renseignements de différents pays au long des quinze dernières années.

Mots-clé: démocratie; Services de Renseignements; régime politique; contrôle extérieur 